\title{
O quesito cor/raça: desafios dos indicadores raciais de mortalidade materna como subsídio ao planejamento de políticas públicas em saúde
}

\author{
Color/race issue: challenges of race-related maternal mortality indicators \\ as important information to elaborate public health policy plans
}

\section{La cuestión color/raza: desafíos de los indicadores raciales de la mortalidad materna como informaciones esenciales para elaboración de proyectos de políticas públicas de salud}

\author{
Denise Carvalho ${ }^{1, a}$ \\ denisecarvalho@usp.br | http://orcid.org/oooo-0001-7569-6127 \\ Daniel Meirinho ${ }^{1, b}$ \\ danielmeirinho@hotmail.com | http://orcid.org/oooo-0002-4658-5556
}

${ }^{1}$ Universidade Federal do Rio Grande do Norte, Programa de Pós-Graduação em Estudos da Mídia. Natal, RN, Brasil.

a Doutorado em Sociologia pela Universidade de São Paulo.

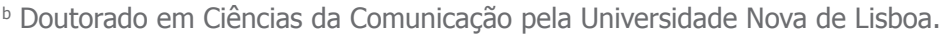

\section{RESUMO}

A pesquisa apresentada neste artigo realizou um balanço quantitativo da taxa de mortalidade materna no Brasil ao longo das últimas duas décadas (2000-2019), sob o recorte de cor/raça com o objetivo de enfatizar a importância da divulgação de informações como demarcadores de mensuração de desigualdades raciais na mortalidade materna de mulheres negras no período gestacional, durante o parto e puerpério. A metodologia compreende a desagregação por cor/raça de dados do Sistema Único de Saúde (MS/DataSUS) derivados do Sistema de Informação de Mortalidade (SIM), a fim de coletar dados referentes a óbitos maternos, e do Sistema de Nascidos Vivos (Sinasc) para os dados relacionados aos nascimentos informados em território nacional. Os resultados obtidos apontam uma tendência de índices de mortalidade materna entre mulheres de cor/raça preta substancialmente maiores do que os que se referem às de cor/raça branca, revelando a falta de informações e políticas que minimizem a condição de vulnerabilidade de alguns grupos étnico-raciais no sistema de atenção à saúde materna.

Palavras-chaves: Mortalidade materna; Dados; Quesito cor/raça; Sistemas de Informação em Saúde; Saúde materna. 


\section{ABSTRACT}

This article presents a quantitative research examining the color/race-related maternal mortality rate in Brazil over the last two decades (2000-2019), aiming to emphasize the importance of the disclosure of information as indicators of racial inequalities in the black women' maternal mortality in the gestational period, during the childbirth and puerperium. The methodology uses the disaggregation by color/race of data from the Sistema Único de Saúde (DataSUS - Unified Health System) derived from the SIM - Sistema de Informação de Mortalidade (Mortality Information System), in order to collect data related to maternal deaths and from the Sinasc - Sistema de Nascidos Vivos (Live Births System), for the data related to births registered in the national territory. The results obtained point to a trend towards the maternal mortality rates being substantially higher among Black race/color women than among White race/color women, revealing the lack of information and policies that minimize the vulnerability of some ethnic-racial groups in the maternal health care system.

Keywords: Maternal mortality; Data; Color/race issue; Health Information Systems; Maternal health.

\section{RESUMEN}

Este artículo presenta una investigación cuantitativa acerca de la tasa de mortalidad materna en Brasil a lo largo de las dos últimas décadas (2000-2019), del punto de vista de color/raza con el objetivo de enfatizar la importancia de la divulgación de informaciones como indicadores de las desigualdades raciales en la mortalidad materna de las mujeres negras en la fase de gestación, en el momento del parto y en el período de puerperio. La metodología utiliza la desagregación por color/raza de los datos del Sistema Único de Saúde (DataSUS - Sistema Unificado de Salud) derivados del SIM - Sistema de Informação de Mortalidade (Sistema de Información sobre Mortalidad), con el fin de recopilar datos relacionados con las muertes maternas, y del Sinasc - Sistema de Nascidos Vivos (Sistema de Nacidos Vivos) para los datos relacionados con los nacimientos documentados en el territorio nacional. Los resultados obtenidos apuntan una tendencia de las tasas de mortalidad materna entre las mujeres de color/raza negra sustancialmente superior a de las mujeres de color/raza blanca, revelando la falta de información y políticas que minimicen la condición de vulnerabilidad de ciertos grupos étnico-raciales en el sistema de atención de salud materna.

Palabras clave: Mortalidad materna; Datos; cuestión color/raza; Sistemas de Información en Salud; Salud materna.

Contribuição dos autores:

Concepção e desenho do estudo: Denise Carvalho e Daniel Meirinho.

Aquisição, análise ou interpretação dos dados: Denise Carvalho e Daniel Meirinho.

Redação do manuscrito: Denise Carvalho e Daniel Meirinho.

Revisão crítica do conteúdo intelectual: Denise Carvalho e Daniel Meirinho.

Declaração de conflito de interesses: não há.

Fontes de financiamento: O presente trabalho foi realizado com apoio da Coordenação de Aperfeiçoamento de Pessoal de Nível Superior - Brasil (CAPES) - Código de Financiamento 001.

Considerações éticas: não há.

Agradecimentos/Contribuições adicionais: não há.

Histórico do artigo: submetido: 26 ago. 2019 | aceito: 03 jun. 2020 | publicado: 30 set. 2020.

Apresentação anterior: não houve.

Licença CC BY-NC atribuição não comercial. Com essa licença é permitido acessar, baixar (download), copiar, imprimir, compartilhar, reutilizar e distribuir os artigos, desde que para uso não comercial e com a citação da fonte, conferindo os devidos créditos de autoria e menção à Reciis. Nesses casos, nenhuma permissão é necessária por parte dos autores ou dos editores. 


\section{INTRODUÇÃO}

A questão da mortalidade materna no Brasil ganhou notoriedade no decorrer dos últimos anos, como resultado da divulgação por parte da Organização das Nações Unidas (ONU) dos 8 Objetivos do Milênio, dentre os quais teve destaque o $5^{\circ}$ Objetivo, intitulado como a 'Melhorar a saúde materna', que inclui como meta a redução da razão de mortalidade materna. A morte materna é a que ocorre durante a gestação ou até 42 dias após o fim da gestação (puerpério). Ela pode ser causada por fatores ligados à gravidez ou agravados por medidas tomadas em relação à gestação' ${ }^{1}$.

Para além dos objetivos elencados nas metas estabelecidas na esfera internacional e doméstica, a importância desta pesquisa é justificada pela evidência de que, quando o acompanhamento adequado é conferido às mães durante a gestação e o parto, a mortalidade materna torna-se um fator evitável, especialmente com relação a mulheres compreendidas na idade fértil (10 a 49 anos). A partir deste pressuposto, é essencial compreender o motivo pelo qual determinados grupos sociais e étnico-raciais estão mais vulneráveis que outros a este tipo específico de mortalidade, de modo que seja possível investigar se estas mortes estão relacionadas a um acompanhamento inadequado e a uma má-qualidade na assistência da saúde da mulher durante a gravidez e no momento do parto. Neste sentido, destaca-se a importância do treinamento e da sensibilização por parte dos profissionais de saúde com relação ao registro dos campos de cor/raça para possibilitar a identificação de assimetrias em estudos analíticos com base neste recorte ${ }^{2}$.

Para que haja um avanço efetivo nos resultados oriundos do tratamento dos dados coletados nos sistemas de informação em saúde, um dos passos primordiais se concentra na própria disponibilização dos dados encontrados nesses sistemas. Nas pautas de discussão do monitoramento e avaliação das políticas de atenção à saúde mais recentes, o registro dos dados segundo o recorte de cor/raça tem sido não só encorajado pelos profissionais de saúde, mas também reconhecido como parte fundamental do procedimento operacional de inserção das informações nos sistemas de informação do campo da saúde. E isto, não apenas como fomento a pesquisas de estudos étnico-raciais, mas como forma de aprimorar os processos de planejamento, gestão e avaliação de políticas de atenção junto a grupos socialmente excluídos e em busca da concretização do acesso mais igualitário dos cidadãos/as brasileiros/as ao direito à informação e à saúde.

\section{O QUESITO COR/RAÇA ENQUANTO INDICADOR}

Desde 2017, os indicadores e dados coletados pelos serviços públicos de saúde devem conter informações sobre cor/raça do usuário do Sistema Único de Saúde (SUS), a partir da autodeclaração do paciente, com o intuito de abastecer os sistemas nacionais de informações, sendo um deles o Sistema de Informações de Mortalidade (SIM). A obrigatoriedade da medida se expande também aos serviços de saúde conveniados ou contratados pelo SUS. Segundo Adorno, Alvarenga e Vasconcellos, o quesito cor passa a ser incorporado ao sistema de informação em saúde a partir de uma demanda dos movimentos sociais negros em torno das "questões acerca das demandas trazidas pela interface saúde pública/raça/etnia como merecedoras de aprofundamento investigativo"3 e informativo ${ }^{3}$. De acordo com os autores, a produção de informações em saúde com o marcador cor/raça passa a ser importante para o reconhecimento de vulnerabilidades que afetam de forma específica a população negra ${ }^{i}$, e assim reconhecidas pelo Estado, assim como a constatação da recorrente ausência de equidade constituem o primeiro passo para a elaboração de estratégias e ações pontuais e exclusivas. Nesta pesquisa, a utilização do termo negro/a está relacionada ao conceito sociológico de raça, apresentando assim, um posicionamento teórico-conceitual que não está fundamentado em uma interpretação biológica. Esta escolha de associação entre o termo negro/a e raça se justifica com base no reconhecimento da noção de raça como um elemento socialmente construído, pois, como afirma Guimarães ${ }^{4}$

i Sendo assim, nesta pesquisa, negros/as $=$ pretos $/$ as + pardos/as. 
"a 'cor' no Brasil funciona como uma imagem figurada de raça", sendo utilizada no Brasil de modo racializado. Em outras palavras, tal como afirma o autor, a cor no Brasil surge acompanhada de um arcabouço ideológico de classificação sócio-cultural dos indivíduos com base na associação de seus fenótipos a uma raça/cor específica. Em complemento a esta justificativa, a utilização do termo negro/a também está associada à junção das categorias de raça/cor preta e parda utilizadas pelo Instituto Brasileiro de Geografia e Estatística (IBGE). A produção de dados no Brasil sobre os usuários negros do SUS é levantada enquanto temática por diferentes autores, como Jaccoud, Lima, Maio e Monteiro, entre outros, que apontam as condições de vulnerabilidade e o reconhecimento da discriminação histórica que a população negra sofreu no Brasil desde a abolição da escravatura até a atualidade nas políticas nacionais de saúde, especificamente como tema deste trabalho, na mortalidade materna da mulher negra ${ }^{5-7}$.

As questões comunicacionais e informacionais afetam a percepção da população sobre o Sistema Único de Saúde enquanto uma política pública de saúde, especificamente pela falta de subsídios informativos e formas sistematicamente assimétricas de divulgação por parte de um grupo de indivíduos que detém o poder da informação de maneira estável, além de excluir a população das decisões e escolhas sobre suas próprias trajetórias e conhecimentos ${ }^{8}$. Reconfigurar o entendimento sobre a saúde pública brasileira envolve necessariamente processos comunicacionais. "É graças à comunicação midiática que o termo SUS hoje está incorporado ao vocabulário da população como uma referência concreta para a resolução de problemas cotidianos ligados à saúde". Por outro lado, esta mesma população ainda não conseguiu apreender claramente qual é seu real alcance e significado para a mudança do sistema brasileiro de saúde, principalmente no campo político9.

A produção de dados informativos para os sistemas nacionais aponta para uma discussão ampliada e participativa dentro da 'equidade em saúde' e para a construção fundamentada de informações que possam vir a subsidiar o planejamento de políticas públicas de saúde que levem em conta as necessidades específicas da população negra. A importância da coleta de informações sobre saúde sob o quesito raça/etnia/cor amplia as problemáticas de investigação no campo da saúde pública ao apresentar a devida complexidade social e contextual relacionada aos critérios étnicos e raciais. A ausência de divulgação destes dados informativos e indicadores pelo sistema nacional de saúde possibilita procedimentos e posturas racializantes, justamente no que toca à desumanização da mulher negra em um contexto de múltiplas representações negativas da pessoa negra na sociedade brasileira, bem como no campo da saúde ${ }^{10}$.

O Brasil, como signatário da Declaração Universal dos Direitos Humanos e da Convenção Internacional sobre a Eliminação de Todas as Formas de Discriminação Racial ${ }^{11}$, deve reconhecer a saúde como um direito de todos os cidadãos e dever do Estado. A barreira do combate à discriminação racial no país é demarcada por estes documentos. A efetivação desses direitos se estende aos princípios de um Sistema Único de Saúde (SUS) universal, igualitário e integral ${ }^{12,13}$. Em 2011, o Ministério da Saúde amplia essa garantia ao instituir a Rede Cegonha ${ }^{14}(\mathrm{RC})$ com o objetivo de assegurar às mulheres o direito ao planejamento reprodutivo, bem como a ampliação do acesso, a melhoria da qualidade da atenção ao pré-natal, ao parto e ao puerpério e a assistência à criança até 24 meses após seu nascimento. Considerar a saúde da mulher negra sob o prisma étnico-racial faz parte um plano de equidade da garantia de direitos à diversidade cultural, étnica e racial e de evidência de "que o racismo pode ser pensado como um determinante social e pode intervir diretamente no processo saúde-doença”"

Nas duas últimas décadas, a taxa de mortalidade materna (TMM) ${ }^{\text {ii }}$ de mulheres negras ${ }^{\mathrm{iii}}$ chega a ser duas vezes maior do que a de mulheres brancas (SIM/DataSUS). Essas mulheres são as que possuem menos

ii Existem várias definições para o indicador 'Razão, Taxa ou Coeficiente de mortalidade materna é o indicador utilizado para conhecer o nível de morte materna [...] calculado pela relação do número de mortes 'maternas' ou de 'mulheres durante a gestação ou até 42 dias após o término da gestação [...].' Onde se lê Taxa de Mortalidade Materna (TMM), também se refere com a mesma definição Razão de Mortalidade Materna (TMM).

iii A terminologia mulher negra abrange as categorias de mulheres de cor preta e parda, respectivamente. 
tempo nas consultas de pré-natal, esperam mais tempo para serem atendidas, são as que menos possuem acompanhantes na hora do parto, por motivo de desautorização do serviço de saúde, e são as que mais têm partos normais (53,3\%), em comparação com 48,8\% das brancas ${ }^{12,15}$. Leal, Gama, Pereira, Pacheco, Carmo e Santos afirmam ainda em suas pesquisas que há um diferencial no uso de analgesia por grupos raciais, possivelmente devido a percepções sociais e dos profissionais da saúde de uma maior resistência à dor de mulheres negras ao serem comparadas com mulheres brancas ${ }^{16}$. Os dados do Sistema de Informações sobre Nascidos Vivos (Sinasc) de 2013 mostram que as mães indígenas, pardas e pretas são as mais jovens do território nacional. A faixa etária de 20 a 24 anos concentra o maior percentual de mães nas populações de raça/cor preta $(26,0 \%)$, parda $(27,5 \%)$ e indígena $(26,8 \%)$.

Embora esses dados necessitem de aprofundamento (especificamente no que se refere ao tempo de espera e aos partos normais, ao se considerar a qualidade do serviço de saúde ofertado pelo SUS em diversas unidades de atendimento), todas essas diferenças são estatisticamente significantes, o que possibilita uma importante constatação das diferenças na assistência dada a usuárias do SUS no quesito cor/raça. É perceptível através de diversos estudos que há um déficit de atenção dos profissionais de saúde por conta da condição de negritude da mulher. É fato que existe um peso do aspecto racial no atendimento à saúde materna e esses indicadores não são apresentados de forma minuciosa pelo Ministério da Saúde, nem tampouco priorizados pela Política Nacional de Saúde Integral da População Negra (PNSIPN). Aprovada em 2006 pelo Conselho Nacional de Saúde (CNS), instituída em 2009 pelo Ministério da Saúde e inserida no Estatuto da Igualdade Racial em 2010, a PNSIPN visa "garantir a equidade e materializar o direito à saúde de negras e negros na busca de redução das iniquidades da saúde materna e infantil no SUS, propondo ações para todas as mulheres sem distinção por raça e cor e/ou classe social"15. Esta ação marca o reconhecimento das desigualdades étnico-raciais e do racismo institucional com vistas à promoção da equidade em saúde.

Para Martins, o estudo da mortalidade materna possui desafios, na atualidade, que superam análises individuais e remetem a uma dimensão maior no âmbito da saúde "numa sociedade onde a igualdade de gênero e direitos reprodutivos ainda não são consenso" ${ }^{2}$. Juntamente com as questões socioeconômicas, a carência de dados que evidencia a vulnerabilidade da mulher negra na assistência de saúde materna sugere que a questão de cor/raça amplifica a falta de entendimento das diferenças e diferenciais raciais/étnicos na manutenção, recuperação e perda da saúde em uma sociedade classista.

Nos últimos anos, houve um crescimento de pessoas que se declararam negrasiv (pretas ou pardas). De acordo com o Censo 2010 do Instituto Brasileiro de Geografia e Estatística (IBGE), negras e negros constituem mais da metade da população brasileira (50,7\%). Dados mais recentes apontam que, em 2015, $53,9 \%$ das pessoas se declararam de cor ou raça preta ou parda ${ }^{17}$. De acordo com o Instituto de Pesquisa Econômica Aplicada (Ipea), em 2008, a população negra representava $67 \%$ do público total atendido pelo SUS, e a branca 47,2\%. A expressiva maioria das pessoas negras não possui plano de saúde $(78,8 \%)$, e menor acesso à saúde significa maior exposição a riscosv. De acordo com dados notificados no Sistema de Informações sobre Mortalidade (SIM), do total de 1.583 mortes maternas em 2012, 60\% eram de mulheres negras e $34 \%$ de brancas.

iv População negra, segundo o Instituto Brasileiro de Geografia e Estatística (IBGE), refere-se à soma das pessoas que se autodeclaram de pele preta ou parda.

v Brasil. Política Nacional de Saúde Integral da População Negra: uma política para o SUS, 3a. ed., Brasília: Editora do Ministério da Saúde, 2017. 


\section{COMUNICAÇÃO E SAÚDE PÚBLICA}

Após mais de três décadas do SUS, é oportuno repensar o papel da comunicação como metodologia estratégica adotada de modo a estimular a participação da população na política de saúde pública para a superação das desigualdades sociais e raciais nas políticas e estratégias de saúde. Comunicação em saúde se faz necessária diante de índices, divulgações e pesquisas que apontam para uma saúde sem educação e prevenção eficazes.

A mídia nacional, especialmente noticiosa, explora basicamente a saúde e o SUS a partir de três enfoques. Uma sobre a construção do SUS-problema ${ }^{18}$, em que os assuntos são apresentados de maneira crítica, opinativa e polêmica, principalmente através de reportagens. A outra forma midiática de disseminação de conteúdos sobre o sistema de saúde é elaborada a partir de seu caráter factual, em que os acontecimentos que assumem uma agenda pública e social são apresentados de forma anunciativa à esfera pública ${ }^{9}$. E o terceiro prisma se dá através de informações de utilidade pública ou de ordem didática, em que assuntos como direitos do cidadão, condições de acesso, serviços, orientações e campanhas públicas de saúde, são rotineiramente apresentados pelos diversos canais de comunicação à sociedade brasileira.

A temática cor/raça foi dada, em um determinado momento político do país, como uma ação estratégica que visava o combate à discriminação racial. Hoje, a ausência de textos oficiais de relatórios da mortalidade materna de mulheres negras no Brasil vem recentemente constituir-se em um dos 'novos' problemas para a investigação e debate público, por meio de reportagens e divulgação dos estudos e dados que relacionam os coeficientes de mortalidade materna por cor/raça. A dificuldade consiste em considerar as diferentes variáveis relacionadas à assistência à saúde da mulher negra ao se analisar a mortalidade materna².

Lefèvre e Lefèvre destacam em seus estudos que a informação é parte do processo de promoção da saúde num processo proativo contínuo de cultura e comunicação que envolva desde os profissionais aos usuários do sistema nacional de saúde para processos de mudanças ${ }^{19}$. A identificação dos avanços e lacunas da Política Nacional de Saúde Integral da População Negra (PNSIPN) dependem do fornecimento de dados para ajudar a delimitar estratégias, incluindo a necessidade de informação de qualidade. O desempenho e impacto desta política pública podem vir a ser mensurados pelos indicadores não coletados e fornecidos pelo SIM com o intuito de proporcionar uma decisão informada e a ação sobre alguns pontos críticos à prestação de um cuidado efetivo, seguro, adequado e equânime no que tocam os procedimentos de saúde materna de mulheres negras.

Entre alguns fatores, os índices na área da saúde pública, assim como as demais ações comunicacionais não midiáticas afetam e modificam a realidade de indivíduos, instituições e organizações sociais ${ }^{7,20}$. A midiatização da sociedade repercute cada vez mais no poder das informações nas práticas de saúde ${ }^{21}$ mediante narrativas capazes de prevenir e afetar as políticas e procedimentos em saúde. Assim, o direito à saúde também é uma relação que pré-requisita o direito à informação. A importância da comunicação e informação para o exercício da cidadania na saúde pública é um fator não apenas de mediação, de orientação, mas também de transformação individual, social, política, econômica e cultural. A utilização, ou não, da informação pode ser um espaço indispensável para identificarmos os movimentos, os reordenamentos da cidadania como direito à informação e à saúde pública e de qualidade.

Ações participativas e uma comunicação informativa passam a ser ferramentas de emancipação, tanto para usuários do SUS quanto para profissionais de saúde, na medida em que é possível reconhecer que a sua ausência constitui um fator de risco para que a população compreenda e assuma seu papel protagonista e não de conformidade 'beneficiária' do SUS.

A transparência online dos dados e indicadores de saúde pelo sistema de informação em saúde necessita ser interpelada por reflexões acerca destes recursos, uma vez que nem toda a população usuária dispõe 
de acesso aos meios eletrônicos, nem de conhecimento para buscar informações sobre os indicadores de saúde, para assim reivindicar melhorias.

\section{ESTRATÉGIA METODOLÓGICA}

A metodologia da pesquisa aqui apresentada compreende a desagregação por cor/raça ${ }^{\text {vi }}$ de dados pertencentes a dois sistemas desenvolvidos pelo Departamento de Informática do Sistema Único de Saúde (DataSUS), o Sistema de Informações sobre Mortalidade (SIM) e o Sistema de Informações sobre Nascidos Vivos (Sinasc). A coleta compreendeu os dados referentes ao Brasil e às suas Unidades Federativas (UF) que foram disponibilizados nos referidos sistemas com relação às últimas décadas, compreendendo assim, o período de 2000 a 2017. Inicialmente foi levada em consideração a possibilidade de coleta de dados dos municípios brasileiros, a fim de identificar possíveis assimetrias. Contudo, a despeito do reconhecimento dos obstáculos da pesquisa em virtude da subnotificação em certas regiões e estados, foi estabelecida como padrão a coleta de informações pertencentes às Unidades Federativas, a fim de manter o objetivo de realizar um diagnóstico com base nos registros dos estados brasileiros ${ }^{1,23}$.

Em 2011, o Ministério da Saúde publicou a quarta edição do "Manual de Instruções para o preenchimento da Declaração de Nascido Vivo"vii , que substituiu a versão de 2001 para o registro de dados do Sistema de Informações sobre Nascidos Vivos (Sinasc). No documento anterior, a indicação padronizava, no campo 32 do formulário da Declaração de Nascido Vivo (DN), o preenchimento obrigatório da indicação raça/ cor como branca, preta, amarela, parda e indígena apenas para a caracterização do recém-nascido. A nova edição de 2011, o Modelo da DN retira a identificação do recém-nascido e insere o registro de raça/cor da mãe, no campo 22, Bloco III do formulário, que passa a atribuir à criança a mesma raça/cor da mãe através da sua autodeclaração. Este é um fenômeno que não possui dados registrados e ainda é pouco estudado, mas pode indicar um expressivo declínio nas taxas de mortalidade de mulheres negras, por não se autodeclararem pretas ou pardas. Reconhecemos que este fator traz importantes limitações nas interpretações dos resultados da análise e pode estar diretamente relacionado ao declínio das taxas de mortalidade de mulheres negras e, consequentemente, de mulheres que se autodeclararam brancas no preenchimento da Declaração de Nascido Vivo, logo após o parto pelo profissional de saúde que prestou assistência ao parto hospitalar ou domiciliar.

Com relação ao Sistema de Informação de Mortalidade (SIM), foi realizada a coleta dos dados brutos referentes a óbitos maternos, compreendidos entre o período selecionado (2000 a 2017) para cada uma das regiões e estados brasileiros. Para tanto, no banco de dados do SIM, foi selecionado no campo da Classificação Internacional de Doenças (CID-10) o Capítulo XV, intitulado 'Causas Maternas', que compreende as causas de morte ocorridas durante a gestação ou até 42 dias após o seu fim ou durante o parto, segundo o tipo de causa obstétrica classificada como 'morte materna obstétrica direta'. Os dados foram coletados por meio do cruzamento de ano e cor/raça, delimitando o conteúdo inserido em 'Óbitos maternos' e o quesito relacionado à morte gravídica ou puerperal em 'Todas as categorias' por região do Brasil e por Unidade Federativa, selecionando as faixas etárias que compreendem mulheres na idade fértil (10 a 49 anos), como forma de contemplar também os casos de gravidez ocorrida durante a adolescência.

A delimitação da idade da mãe também compreendeu o critério de selecionar os casos ocorridos com mães na idade fértil (10 a 49 anos), por região do Brasil e Unidade Federativa. O segundo sistema de acesso utilizado foi o Sistema de Nascidos Vivos (Sinasc), banco de registros administrado pelo Centro

\footnotetext{
vi A variável cor/raça foi caracterizada de acordo com a classificação do Instituto Brasileiro de Geografia e Estatística (IBGE) como: branca, preta, parda, amarela e indígena ${ }^{22}$.

vii Ministério da Saúde (BR). Manual de instruções para o preenchimento da declaração de nascido vivo. 4. ed. Brasília: MS, Secretaria de Vigilância em Saúde; 2011. [Internet]. [acessado 14 set. 2019]. Disponível em: http://portalarquivos.saude.gov.br/ images/pdf/2017/junho/08/inst_dn.pdf
} 
Nacional de Epidemiologia (Cenepi), órgão pertencente ao Ministério da Saúde. Os dados registrados no Sinasc resultam das declarações de nascidos vivos preenchidos pelos órgãos de saúde onde ocorreram os nascimentos provenientes de partos domiciliares informados em território nacional pelos cartórios. Para a pesquisa, foram coletados os dados brutos de nascidos vivos, inseridos no quesito cor/raça, por residência da mãe no período de 2000 a 2017. Coletados os valores brutos para posterior análise, foi calculada a razão da mortalidade materna por 100.00o habitantes em cada região. Este cálculo é resultado da divisão entre o número bruto de óbitos maternos específicos de cada categoria de cor/raça e o número bruto de nascidos vivos pertencentes à categoria de cor/raça equivalente, sendo o resultado desta razão multiplicado por 100.000 e corrigido (multiplicado) pelo fator 1,42 para as Regiões Norte, Nordeste, Centro-Oeste ${ }^{24}$.

Conforme demonstram os gráficos que serão apresentados no decorrer deste artigo, a coleta de dados foi realizada a cada ano, no período de 2000 a 2017. Porém, diante da necessidade de apresentação de alguns dados por meio de tabelas - no caso, das taxas de mortalidade materna referentes às cinco regiões brasileiras e aos estados das regiões Norte e Nordeste - também surgiu a necessidade de otimização no processo de apresentação desses valores. Assim, a partir dessas demandas, foi efetuada uma escolha acerca de quais dados relacionados a esta pesquisa seriam demonstrados nas mencionadas tabelas. Como a amostra da pesquisa se refere a uma coleta de 17 anos de registros de mortalidade materna do Sistema de Informação de Mortalidade (SIM), foi necessário realizar um ajuste na apresentação dos dados das referidas tabelas, apresentadas a partir desta decisão, com o intervalo de dois anos. Esta adaptação foi escolhida como uma forma evitar que a apresentação de todo o período assumisse um aspecto excessivamente extenso. Contudo, é preciso demarcar que durante esse período diversas variáveis relativas à condução do Ministério da Saúde sobre várias temáticas, incluindo a classificação raça/cor envolvem ainda estruturas políticas e administrativas de cinco governos presidenciais no país. Deste modo, a escolha do agrupamento e apresentação dos gráficos pelos respectivos estados e regiões ocorre de forma aleatória, demarcada pelo objetivo de fornecer uma melhor capacidade de leitura dos resultados.

\section{RESULTADOS}

Uma ressalva inicial que deve ser feita em conjunto com a análise das taxas de mortalidade materna é a observação dos dados populacionais. Embora o estudo proposto por esta pesquisa apresente uma série temporal de quase duas décadas, o último Censo Demográfico publicado pelo IBGE ${ }^{\text {viii }}$ (2010) retrata, ao ser utilizado como parâmetro, que, comparadas à população total, o percentual de mulheres que se autoclassifica como pretas não chega a ultrapassar $5 \%$, tanto com relação ao Brasil como um todo quanto com relação às suas cinco regiões. Contudo, as análises apresentadas a seguir comprovam que são estas mulheres que apresentam taxas significativas quando o quesito cor/raça é considerado para a análise das taxas de mortalidade materna. Este aspecto reitera a importância da divulgação dos dados considerando o quesito cor/raça nos sistemas de informação em saúde, não apenas no que concerne à divulgação dos dados de mortalidade, mas também com respeito ao cruzamento destes com os demais registros socioeconômicos, de modo que a análise conjunta destas informações contribua para a elaboração de diagnósticos que sejam capazes de retratar as desigualdades que estão histórica e socialmente estruturadas na sociedade brasileira.

A Figura 1, a Figura 2 (agrupadas entre si de forma aleatória) e a Tabela 1 (apresentada em um recorte bianual, estipulado aleatoriamente em virtude do significativo intervalo temporal dos dados) demonstram que na distribuição das taxas de mortalidade materna (TMM) por regiões as TMM de mulheres de cor/raça preta se destacam ao longo da série com relação às demais categorias de cor/raça na maioria das regiões, com exceção apenas da Região Sul, que apresenta destaque com relação às TMM de mulheres de cor/ raça amarela e indígena, respectivamente, em virtude da subnotificação de dados para estas categorias,

viii Dados acessados em https://sidra.ibge.gov.br/Tabela/3175\#resultado. 
demonstrados por meio dos valores equivalentes a o (zero). Vale ressaltar que, em alguns períodos da série, as regiões Norte, Nordeste e Centro-Oeste apresentam as maiores taxas com relação a mulheres de cor/raça preta, quando comparadas às demais regiões. Nas cinco regiões brasileiras, os dados apresentam com destaque, as segundas maiores proporções das TMM entre mulheres de cor/raça indígena. Também é possível observar, com poucas variações, que as TMM de mulheres brancas são as menores na maioria das regiões, comprovando sua menor vulnerabilidade com relação às mortes maternas. Apesar das oscilações ao longo do período, é possível observar um movimento de diminuição das TMM de mulheres de cor/ raça preta na transição de 2009 para 2010 nas regiões Norte e Nordeste. Na Região Sul é perceptível que, com algumas oscilações, as TMM de cor/raça preta e parda apresentam movimentos muito semelhantes com uma tendência de redução na transição de 2009 para 2010, ao passo que na Região Centro-Oeste este movimento de diminuição ocorre na transição de 2010 para 2011. As TMM de mulheres brancas demonstram um movimento semelhante às TMM de mulheres pardas nas regiões Norte, Nordeste, Sudeste e Centro-Oeste, com algumas variações. É importante registrar a ressalva de que as oscilações nas TMM de mulheres indígenas e de cor/raça amarela ocorrem, em parte, pelo sub-registro de dados com relação a estas populações.

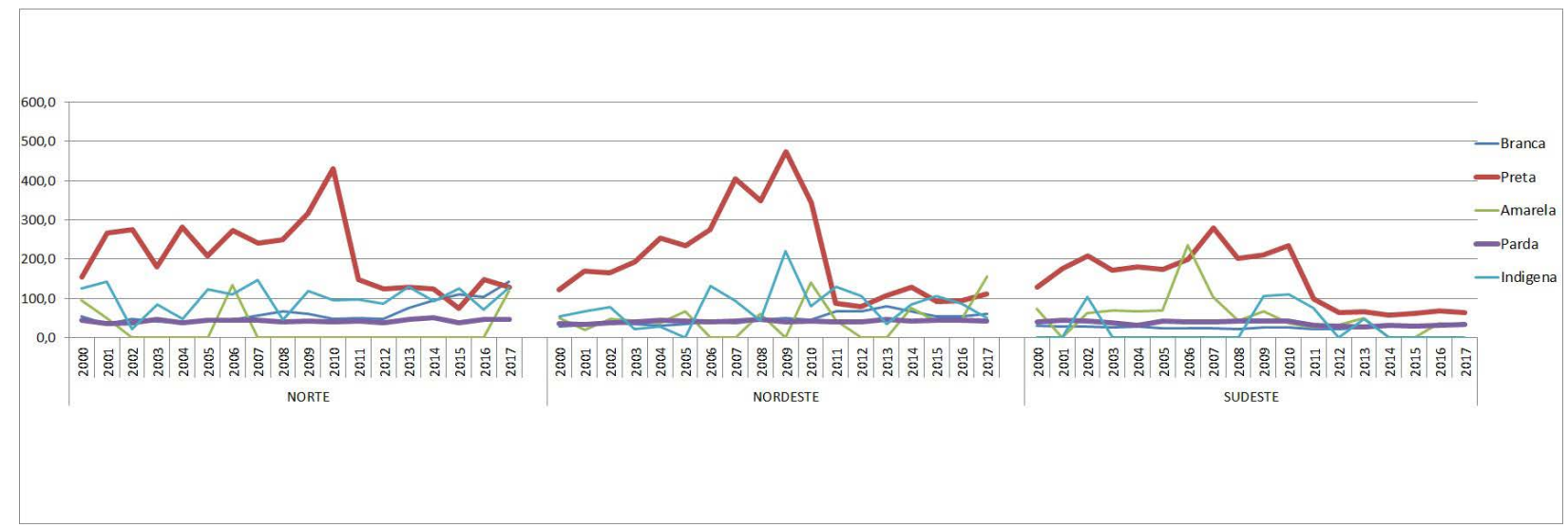

Figura 1 - Taxa de Mortalidade Materna, segundo Cor/Raça, p/ 100.000 hab. Brasil por regiões, Regiões Norte, Nordeste e Sudeste, 2000 a 2017

Fontes: MS/SVS/CGIAE - Sistema de Informações sobre Mortalidade - SIM

MS/SVS/DASIS - Sistema de Informações sobre Nascidos Vivos - Sinasc

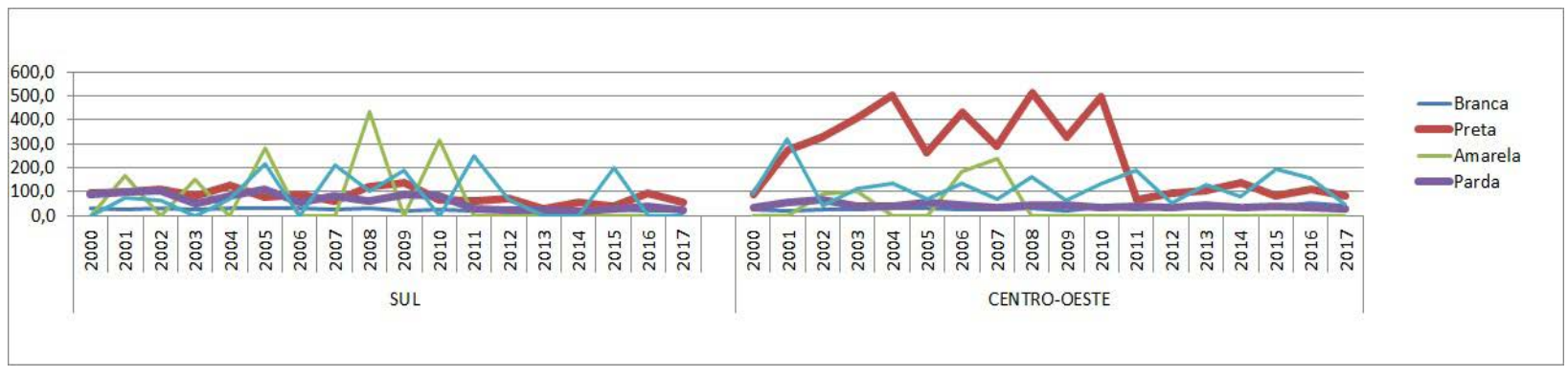

Figura 2 - Taxa de Mortalidade Materna, segundo Cor/Raça, p/ 100.000 hab. Brasil por regiões, Regiões Sul e CentroOeste, 2000 a 2017

Fontes: MS/SVS/CGIAE - Sistema de Informações sobre Mortalidade - SIM

MS/SVS/DASIS - Sistema de Informações sobre Nascidos Vivos - Sinasc 
Tabela 1 - Taxa de mortalidade materna, segundo cor/raça, p/100.000 nascidos vivos Brasil por regiões, 2000 a 2017 (versão resumida com intervalo de dois anos)

\begin{tabular}{|c|c|c|c|c|c|c|c|c|c|c|}
\hline \multicolumn{11}{|c|}{ REGIÃO NORTE } \\
\hline Cor/Raça & 2000 & 2002 & 2004 & 2006 & 2008 & 2010 & 2012 & 2014 & 2016 & 2017 \\
\hline Branca & 53,8 & 46,7 & 39,2 & 44,4 & 66,6 & 48,5 & 46,5 & 93,9 & 103,5 & 141,6 \\
\hline Preta & 153,5 & 275,1 & 280,7 & 272,8 & 248,9 & 430,0 & 123,8 & 123,3 & 146,7 & 127,3 \\
\hline Amarela & 95,7 & 0,0 & 0,0 & 133,5 & 0,0 & 0,0 & 0,0 & 0,0 & 0,0 & 118,5 \\
\hline Parda & 45,2 & 36,7 & 38,2 & 43,9 & 38,9 & 39,8 & 38,0 & 50,4 & 46,1 & 45,3 \\
\hline Indígena & 126,0 & 21,9 & 47,8 & 110,2 & 44,6 & 95,2 & 87,0 & 91,8 & 70,3 & 127,6 \\
\hline \multicolumn{11}{|c|}{ REGIÃO NORDESTE } \\
\hline Cor/Raça & 2000 & 2002 & 2004 & 2006 & 2008 & 2010 & 2012 & 2014 & 2016 & 2017 \\
\hline Branca & 28,2 & 38,2 & 30,0 & 40,5 & 46,1 & 44,8 & 66,0 & 66,7 & 54,6 & 60,8 \\
\hline Preta & 122,4 & 164,0 & 252,5 & 274,9 & 349,2 & 343,6 & 79,6 & 127,9 & 94,3 & 111,0 \\
\hline Amarela & 48,5 & 46,3 & 35,5 & 0,0 & 59,7 & 140,9 & 0,0 & 75,0 & 47,4 & 156,4 \\
\hline Parda & 36,6 & 37,5 & 44,8 & 39,2 & 45,7 & 42,8 & 40,6 & 42,3 & 43,2 & 42,9 \\
\hline Indígena & 54,4 & 76,7 & 27,2 & 132,6 & 42,4 & 79,9 & 104,8 & 84,0 & 86,9 & 48,6 \\
\hline \multicolumn{11}{|c|}{ REGIÃO SUDESTE } \\
\hline Cor/Raça & 2000 & 2002 & 2004 & 2006 & 2008 & 2010 & 2012 & 2014 & 2016 & 2017 \\
\hline Branca & 29,5 & 27,3 & 27,8 & 23,8 & 22,5 & 24,8 & 21,1 & 27,1 & 30,7 & 37,3 \\
\hline Preta & 127,6 & 207,4 & 179,2 & 200,3 & 202,3 & 234,4 & 63,8 & 56,8 & 67,2 & 64,0 \\
\hline Amarela & 74,3 & 62,9 & 66,0 & 234,3 & 43,9 & 35,9 & 32,0 & 0,0 & 35,8 & 32,6 \\
\hline Parda & 40,3 & 42,3 & 31,7 & 40,7 & 41,9 & 41,6 & 28,5 & 31,3 & 30,9 & 33,2 \\
\hline Indígena & 0,0 & 104,4 & 0,0 & 0,0 & 0,0 & 109,8 & 0,0 & 0,0 & 0,0 & 0,0 \\
\hline \multicolumn{11}{|c|}{ REGIÃO SUL } \\
\hline Cor/Raça & 2000 & 2002 & 2004 & 2006 & 2008 & 2010 & 2012 & 2014 & 2016 & 2017 \\
\hline Branca & 31,1 & 30,1 & 32,4 & 32,6 & 29,5 & 26,2 & 28,2 & 21,0 & 22,5 & 20,0 \\
\hline Preta & 92,3 & 112,9 & 126,4 & 91,2 & 121,3 & 67,0 & 75,0 & 54,6 & 92,9 & 54,5 \\
\hline Amarela & 0,0 & 0,0 & 0,0 & 0,0 & 434,8 & 316,5 & 0,0 & 0,0 & 0,0 & 0,0 \\
\hline Parda & 89,1 & 103,9 & 85,5 & 57,5 & 63,2 & 82,1 & 23,3 & 18,9 & 39,8 & 25,7 \\
\hline Indígena & 0,0 & 66,3 & 72,6 & 0,0 & 104,9 & 0,0 & 71,5 & 0,0 & 0,0 & 0,0 \\
\hline \multicolumn{11}{|c|}{ REGIÃO CENTRO-OESTE } \\
\hline Cor/Raça & 2000 & 2002 & 2004 & 2006 & 2008 & 2010 & 2012 & 2014 & 2016 & 2017 \\
\hline Branca & 24,7 & 27,1 & 33,2 & 24,7 & 34,0 & 39,9 & 39,8 & 37,7 & 54,7 & 42,4 \\
\hline Preta & 89,3 & 328,0 & 504,2 & 431,7 & 512,0 & 495,8 & 93,0 & 137,6 & 113,6 & 84,6 \\
\hline Amarela & 0,0 & 89,1 & 0,0 & 184,5 & 0,0 & 0,0 & 0,0 & 0,0 & 0,0 & 0,0 \\
\hline Parda & 36,4 & 65,5 & 37,7 & 43,3 & 43,7 & 33,6 & 35,4 & 34,7 & 36,8 & 29,8 \\
\hline Indígena & 90,9 & 40,6 & 135,0 & 135,0 & 160,2 & 132,7 & 52,7 & 78,3 & 157,6 & 47,9 \\
\hline
\end{tabular}

Fontes: MS/SVS/CGIAE - Sistema de Informações sobre Mortalidade - SIM MS/SVS/DASIS - Sistema de Informações sobre Nascidos Vivos - Sinasc

Conforme relatam algumas pesquisas ${ }^{23,25}$ que tratam da mensuração das taxas de mortalidade materna no Brasil, há regiões que apresentam os problemas do sub-registro de óbitos e da subinformação (especialmente com relação à má definição das causas desses óbitos), comprometendo a possibilidade de uma análise dos dados desagregados por cor/raça. Contudo, o diagnóstico prévio que pode ser feito é a 
necessidade de melhoria no registro destas informações. Este fato é comprovado nas análises que serão apresentados a seguir.

A Figura 3, a Figura 4 e a Figura 5 apresentam as taxas de mortalidade materna nos estados da Região Norte. A disposição dos gráficos e o agrupamento entre os estados foi feita de modo aleatório. Apesar da identificação desta região como sendo uma das que apresenta as maiores TMM com relação a mulheres de cor/raça preta, em conjunto com as regiões Nordeste e Centro-Oeste, os dados apresentados na Tabela 2 revelam uma incidência recorrente da ausência de registros nos sistemas de informação de saúde nos quesitos de cor/raça branca, preta e amarela, o que resulta nos dados com valores equivalentes a o (zero). Os registros dos estados de Rondônia, Pará e Roraima apresentaram ausência de dados para o cálculo das TMM de mulheres de cor/raça amarela. O movimento das TMM de mulheres de cor/raça branca e parda é semelhante, sendo ultrapassados na maioria dos estados pelas TMM das mulheres indígenas.

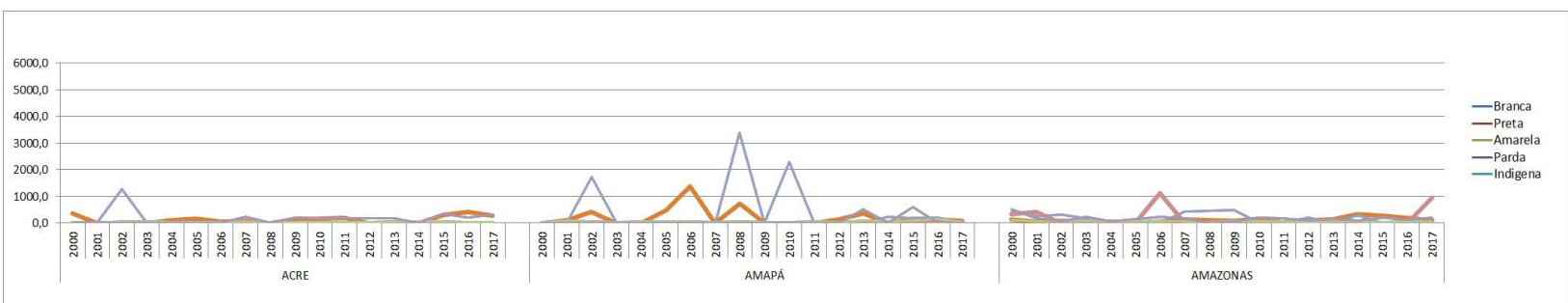

Figura 3 - Taxa de Mortalidade Materna, segundo Cor/Raça, p/ 100.000 hab. Região Norte, estados do Acre, Amapá e Amazonas, 2000 a 2017

Fontes: MS/SVS/CGIAE - Sistema de Informações sobre Mortalidade - SIM

MS/SVS/DASIS - Sistema de Informações sobre Nascidos Vivos - Sinasc

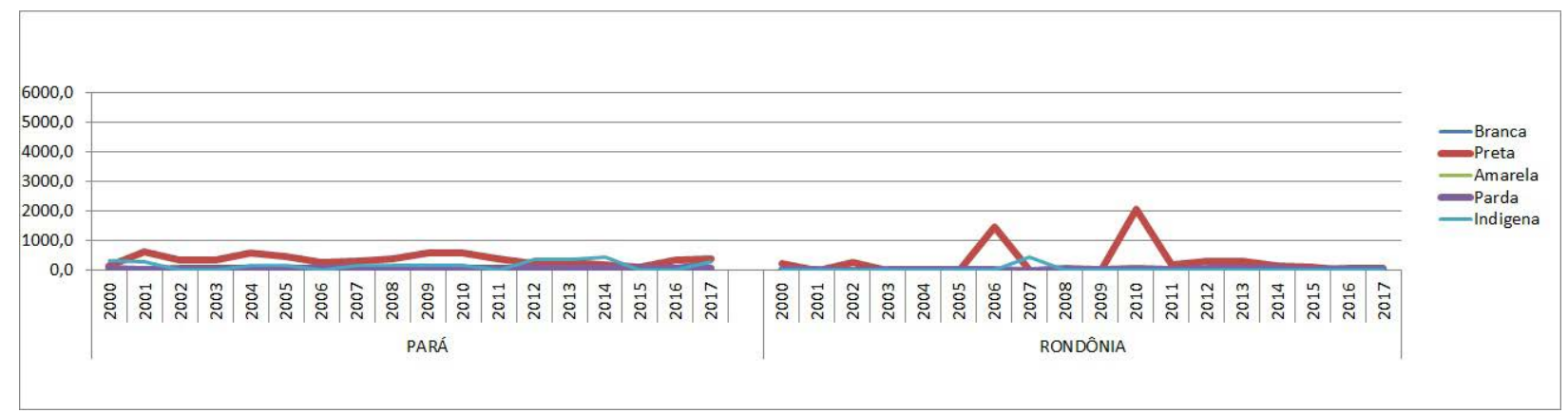

Figura 4 - Taxa de Mortalidade Materna, segundo Cor/Raça, p/ 100.000 hab. Região Norte, estados do Pará e Rondônia, 2000 a 2017

Fontes: MS/SVS/CGIAE - Sistema de Informações sobre Mortalidade - SIM

MS/SVS/DASIS - Sistema de Informações sobre Nascidos Vivos - Sinasc

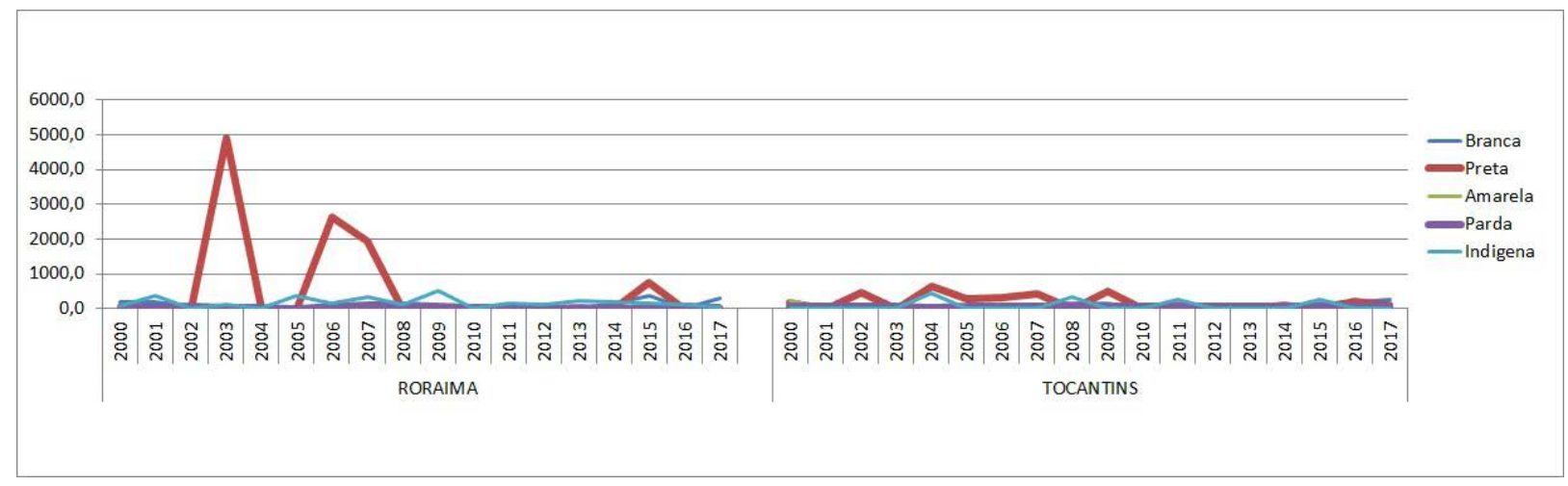

Figura 5 - Taxa de Mortalidade Materna, segundo Cor/Raça, p/ 100.000 hab. Região Norte, estados de Roraima e Tocantins, 2000 a 2017

Fontes: MS/SVS/CGIAE - Sistema de Informações sobre Mortalidade - SIM

MS/SVS/DASIS - Sistema de Informações sobre Nascidos Vivos - Sinasc 
Tabela 2 - Taxa de mortalidade materna, segundo cor/raça, $p / 100.000$ nascidos vivos nos estados da Região Norte, 2000 a 2017 (versão resumida com intervalo de dois anos)

(continua)

\begin{tabular}{|c|c|c|c|c|c|c|c|c|c|c|}
\hline \multicolumn{11}{|l|}{ RONDÔNIA } \\
\hline Cor/Raça & 2000 & 2002 & 2004 & 2006 & 2008 & 2010 & 2012 & 2014 & 2016 & 2017 \\
\hline Branca & 19,8 & 67,2 & 13,3 & 57,9 & 43,7 & 15,4 & 44,0 & 110,9 & 88,8 & 139,2 \\
\hline Preta & 240,7 & 285,7 & 0,0 & 1449,0 & 0,0 & 2048,1 & 304,7 & 145,5 & 0,0 & 0,0 \\
\hline Amarela & 0,0 & 0,0 & 0,0 & 0,0 & 0,0 & 0,0 & 0,0 & 0,0 & 0,0 & 0,0 \\
\hline Parda & 37,7 & 9,6 & 17,7 & 40,0 & 63,2 & 64,8 & 66,0 & 84,2 & 62,9 & 58,6 \\
\hline Indígena & 0,0 & 0,0 & 0,0 & 0,0 & 0,0 & 0,0 & 0,0 & 0,0 & 0,0 & 0,0 \\
\hline \multicolumn{11}{|l|}{ ACRE } \\
\hline COR/RAÇA & 2000 & 2002 & 2004 & 2006 & 2008 & 2010 & 2012 & 2014 & 2016 & 2017 \\
\hline Branca & 339,8 & 0,0 & 89,8 & 51,8 & 0,0 & 166,6 & 0,0 & 0,0 & 398,1 & 256,8 \\
\hline Preta & 0,0 & 1267,9 & 0,0 & 0,0 & 0,0 & 0,0 & 0,0 & 0,0 & 0,0 & 0,0 \\
\hline Amarela & 0,0 & 0,0 & 0,0 & 0,0 & 0,0 & 0,0 & 0,0 & 0,0 & 0,0 & 0,0 \\
\hline Parda & 24,8 & 43,4 & 40,2 & 23,1 & 31,4 & 31,7 & 23,1 & 52,4 & 34,5 & 31,8 \\
\hline Indígena & 0,0 & 0,0 & 0,0 & 0,0 & 0,0 & 169,7 & 171,1 & 0,0 & 205,8 & 318,0 \\
\hline \multicolumn{11}{|l|}{ AMAZONAS } \\
\hline Cor/Raça & 2000 & 2002 & 2004 & 2006 & 2008 & 2010 & 2012 & 2014 & 2016 & 2017 \\
\hline Branca & 129,1 & 63,5 & 32,2 & 46,2 & 101,7 & 164,3 & 91,7 & 335,6 & 172,1 & 86,8 \\
\hline Preta & 465,6 & 324,2 & 0,0 & 0,0 & 456,6 & 0,0 & 204,9 & 279,5 & 0,0 & 0,0 \\
\hline Amarela & 315,6 & 0,0 & 0,0 & 1127,0 & 0,0 & 0,0 & 0,0 & 0,0 & 0,0 & 953,0 \\
\hline Parda & 101,5 & 53,6 & 63,8 & 62,8 & 38,7 & 66,3 & 40,2 & 69,6 & 58,0 & 51,4 \\
\hline Indígena & 508,6 & 66,6 & 49,3 & 238,9 & 0,0 & 200,1 & 97,0 & 88,5 & 125,0 & 211,7 \\
\hline \multicolumn{11}{|l|}{ RORAIMA } \\
\hline Cor/Raça & 2000 & 2002 & 2004 & 2006 & 2008 & 2010 & 2012 & 2014 & 2016 & 2017 \\
\hline Branca & 196,0 & 76,3 & 0,0 & 62,2 & 0,0 & 0,0 & 0,0 & 165,5 & 0,0 & 296,1 \\
\hline Preta & 0,0 & 0,0 & 0,0 & 2629,6 & 0,0 & 0,0 & 0,0 & 0,0 & 0,0 & 0,0 \\
\hline Amarela & 0,0 & 0,0 & 0,0 & 0,0 & 0,0 & 0,0 & 0,0 & 0,0 & 0,0 & 0,0 \\
\hline Parda & 70,2 & 43,1 & 20,6 & 51,7 & 105,5 & 21,4 & 0,0 & 0,0 & 56,9 & 35,3 \\
\hline Indígena & 68,2 & 0,0 & 0,0 & 163,8 & 130,9 & 0,0 & 118,4 & 196,9 & 103,2 & 59,1 \\
\hline \multicolumn{11}{|l|}{ PARÁ } \\
\hline Cor/Raça & 2000 & 2002 & 2004 & 2006 & 2008 & 2010 & 2012 & 2014 & 2016 & 2017 \\
\hline Branca & 42,1 & 72,5 & 91,9 & 63,9 & 136,4 & 50,4 & 91,3 & 121,3 & 152,3 & 288,8 \\
\hline Preta & 157,9 & 339,2 & 609,8 & 267,8 & 411,0 & 611,0 & 216,1 & 195,8 & 336,9 & 410,0 \\
\hline Amarela & 0,0 & 0,0 & 0,0 & 0,0 & 0,0 & 0,0 & 0,0 & 0,0 & 0,0 & 0,0 \\
\hline Parda & 59,9 & 57,4 & 64,0 & 72,6 & 57,8 & 61,2 & 68,3 & 82,4 & 65,7 & 81,0 \\
\hline Indígena & 326,4 & 0,0 & 165,3 & 0,0 & 179,5 & 170,5 & 353,5 & 440,7 & 0,0 & 303,2 \\
\hline \multicolumn{11}{|l|}{ AMAPÁ } \\
\hline Cor/Raça & 2000 & 2002 & 2004 & 2006 & 2008 & 2010 & 2012 & 2014 & 2016 & 2017 \\
\hline Branca & 0,0 & 400,6 & 0,0 & 1378,6 & 724,5 & 0,0 & 127,1 & 0,0 & 131,5 & 63,8 \\
\hline Preta & 0,0 & 1731,7 & 0,0 & 0,0 & 3381,0 & 2290,3 & 0,0 & 218,1 & 204,0 & 0,0 \\
\hline Amarela & 0,0 & 0,0 & 0,0 & 0,0 & 0,0 & 0,0 & 0,0 & 0,0 & 0,0 & 0,0 \\
\hline Parda & 42,1 & 53,9 & 42,6 & 49,7 & 57,9 & 21,9 & 33,2 & 64,8 & 140,6 & 60,1 \\
\hline Indígena & 0,0 & 0,0 & 0,0 & 0,0 & 0,0 & 0,0 & 0,0 & 0,0 & 0,0 & 0,0 \\
\hline
\end{tabular}


(conclusão)

\begin{tabular}{lllllllllll}
\hline TOCANTINS & & & & & & & & & & \\
\hline Cor/Raça & $\mathbf{2 0 0 0}$ & $\mathbf{2 0 0 2}$ & $\mathbf{2 0 0 4}$ & $\mathbf{2 0 0 6}$ & $\mathbf{2 0 0 8}$ & $\mathbf{2 0 1 0}$ & $\mathbf{2 0 1 2}$ & $\mathbf{2 0 1 4}$ & $\mathbf{2 0 1 6}$ & $\mathbf{2 0 1 7}$ \\
Branca & 103,4 & 23,2 & 58,6 & 63,2 & 113,7 & 0,0 & 0,0 & 87,1 & 197,4 & 269,6 \\
Preta & 181,8 & 462,5 & 621,4 & 324,2 & 0,0 & 0,0 & 0,0 & 114,1 & 220,5 & 85,2 \\
Amarela & 219,8 & 0,0 & 0,0 & 0,0 & 0,0 & 0,0 & 0,0 & 0,0 & 0,0 & 0,0 \\
Parda & 49,8 & 60,6 & 28,7 & 48,3 & 80,6 & 44,2 & 52,6 & 43,9 & 68,1 & 44,6 \\
Indígena & 0,0 & 0,0 & 431,6 & 0,0 & 334,1 & 0,0 & 0,0 & 0,0 & 0,0 & 0,0 \\
\hline
\end{tabular}

Fontes: MS/SVS/CGIAE - Sistema de Informações sobre Mortalidade - SIM MS/SVS/DASIS - Sistema de Informações sobre Nascidos Vivos - Sinasc

A Figura 6, a Figura 7 e a Figura 8 expressam as TMM relacionadas à Região Nordeste. A seleção dos estados em cada agrupamento de gráficos é aleatória. Vale relembrar que esta região compõe a que apresenta as maiores TMM de mulheres de cor/raça preta do Brasil, juntamente com as regiões Norte e CentroOeste. Contudo, conforme os registros da Tabela 3, é possível identificar a ausência alternada de registros - representada pelos dados equivalentes a o (zero) - nos sistemas de informação de saúde nos quesitos de cor/raça preta, indígena e amarela, principalmente nos estados de Alagoas, Paraíba e Rio Grande do Norte. É possível observar que a totalidade dos estados revela destaque entre as taxas relacionadas a mulheres de cor/raça preta, com movimentos de crescimento na maioria dos estados entre 2000 e 2010 - entrecortados por algumas oscilações - e um movimento de decréscimo na transição entre 2009 e 2010, assim como ocorre na maioria das regiões do Brasil. Os estados do Rio Grande do Norte e Sergipe não apresentaram registros para cálculo das TMM relacionadas à cor/raça amarela, o que é perceptível nos dados com valor o (zero) como resultado desta subnotificação. Em termos gerais, aparentemente, os movimentos das TMM para mulheres de cor/raça branca e parda são similares, sendo ultrapassados em determinados momentos da série pelas TMM de mulheres indígenas. Como resultado dos picos isolados retratados por vezes nos gráficos, outro fator que precisa ser levado em consideração para esta região é a recorrente ausência de registros de dados relacionados a mulheres de cor/raça preta, amarela e indígena, respectivamente, resultando, de certa forma, no comprometimento da análise das informações registradas nos sistemas de informação de saúde.

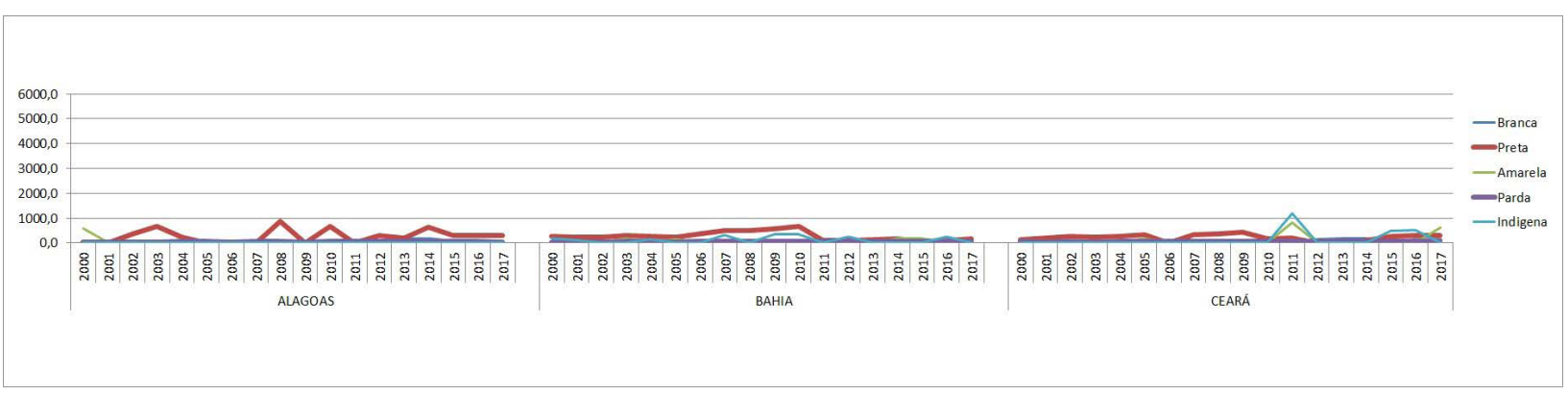

Figura 6 - Taxa de Mortalidade Materna, segundo Cor/Raça, p/ 100.000 hab. Região Nordeste, estados de Alagoas, Bahia e Ceará, 2000 a 2017

Fontes: MS/SVS/CGIAE - Sistema de Informações sobre Mortalidade - SIM

MS/SVS/DASIS - Sistema de Informações sobre Nascidos Vivos - Sinasc 


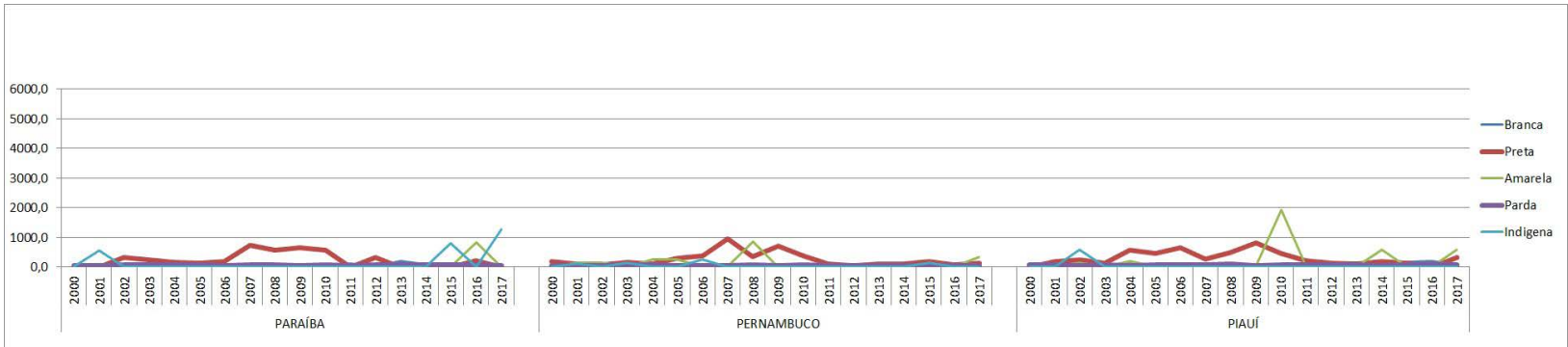

Figura 7: Taxa de Mortalidade Materna, segundo Cor/Raça, p/ 100.000 hab. Região Nordeste, estados da Paraíba, Pernambuco e Piauí, 2000 a 2017

Fontes: MS/SVS/CGIAE - Sistema de Informações sobre Mortalidade - SIM

MS/SVS/DASIS - Sistema de Informações sobre Nascidos Vivos - Sinasc

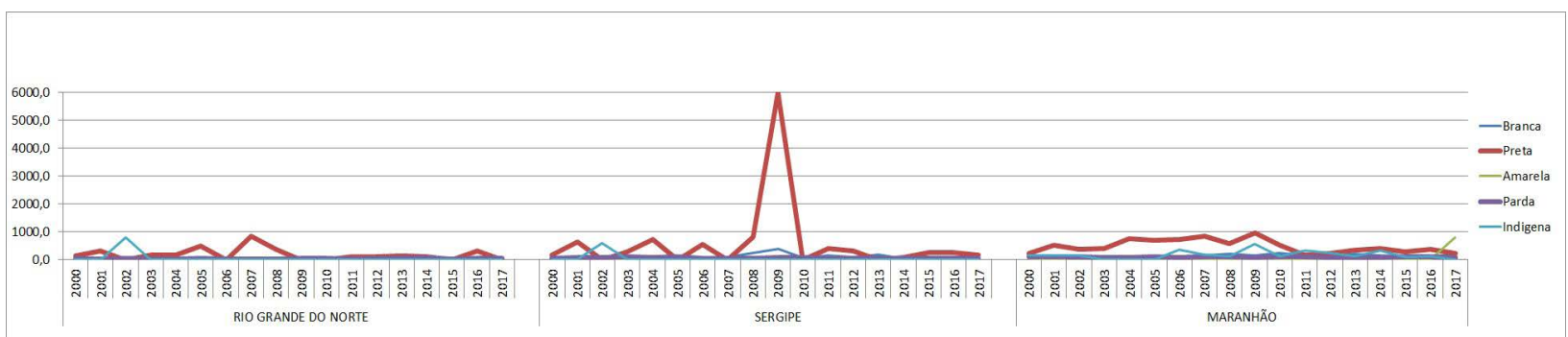

Figura 8 - Taxa de Mortalidade Materna, segundo Cor/Raça, p/ 100.000 hab. Região Nordeste, estados do Rio Grande do Norte, Sergipe e Maranhão, 2000 a 2017

Fontes: MS/SVS/CGIAE - Sistema de Informações sobre Mortalidade - SIM

MS/SVS/DASIS - Sistema de Informações sobre Nascidos Vivos - Sinasc

Tabela 3 - Taxa de mortalidade materna, segundo cor/raça, $p / 100.000$ nascidos vivos nos estados da Região Nordeste, 2000 a 2017 (versão resumida com intervalo de dois anos)

(continua)

\begin{tabular}{lllllllllll}
\hline MARANHÃO & & & & & & & & & & \\
\hline Cor/Raça & $\mathbf{2 0 0 0}$ & $\mathbf{2 0 0 2}$ & $\mathbf{2 0 0 4}$ & $\mathbf{2 0 0 6}$ & $\mathbf{2 0 0 8}$ & $\mathbf{2 0 1 0}$ & $\mathbf{2 0 1 2}$ & $\mathbf{2 0 1 4}$ & $\mathbf{2 0 1 6}$ & $\mathbf{2 0 1 7}$ \\
Branca & 50,8 & 112,8 & 59,2 & 126,5 & 221,2 & 236,9 & 131,1 & 141,2 & 120,9 & 180,0 \\
Preta & 238,4 & 360,1 & 763,7 & 725,2 & 579,2 & 505,3 & 213,7 & 406,8 & 362,0 & 229,6 \\
Amarela & 70,5 & 132,7 & 0,0 & 0,0 & 0,0 & 0,0 & 0,0 & 0,0 & 0,0 & 806,8 \\
Parda & 108,9 & 106,2 & 88,4 & 81,8 & 97,4 & 100,9 & 73,6 & 71,3 & 100,3 & 79,9 \\
Indígena & 166,7 & 153,2 & 0,0 & 357,7 & 138,1 & 120,9 & 236,5 & 336,2 & 116,6 & 0,0 \\
\hline PIAUÍ & & & & & & & & & & \\
\hline Cor/Raça & $\mathbf{2 0 0 0}$ & $\mathbf{2 0 0 2}$ & $\mathbf{2 0 0 4}$ & $\mathbf{2 0 0 6}$ & $\mathbf{2 0 0 8}$ & $\mathbf{2 0 1 0}$ & $\mathbf{2 0 1 2}$ & $\mathbf{2 0 1 4}$ & $\mathbf{2 0 1 6}$ & $\mathbf{2 0 1 7}$ \\
Branca & 75,8 & 61,0 & 102,2 & 61,1 & 77,4 & 39,5 & 72,8 & 75,1 & 189,8 & 87,6 \\
Preta & 0,0 & 249,7 & 557,8 & 650,8 & 483,5 & 458,1 & 113,8 & 188,0 & 0,0 & 315,0 \\
Amarela & 125,6 & 144,3 & 199,4 & 0,0 & 0,0 & 1918,9 & 0,0 & 586,8 & 0,0 & 574,9 \\
Parda & 66,2 & 45,3 & 48,2 & 70,3 & 103,0 & 58,5 & 75,6 & 57,6 & 98,9 & 80,6 \\
Indígena & 0,0 & 574,9 & 0,0 & 0,0 & 0,0 & 0,0 & 0,0 & 0,0 & 0,0 & 0,0 \\
\hline CEARÁ & & & & & & & & & & \\
\hline Cor/Raça & $\mathbf{2 0 0 0}$ & $\mathbf{2 0 0 2}$ & $\mathbf{2 0 0 4}$ & $\mathbf{2 0 0 6}$ & $\mathbf{2 0 0 8}$ & $\mathbf{2 0 1 0}$ & $\mathbf{2 0 1 2}$ & $\mathbf{2 0 1 4}$ & $\mathbf{2 0 1 6}$ & $\mathbf{2 0 1 7}$ \\
Branca & 62,4 & 91,6 & 30,2 & 54,4 & 52,4 & 66,5 & 158,6 & 180,7 & 154,1 & 111,7 \\
Preta & 129,9 & 253,6 & 277,3 & 0,0 & 372,2 & 149,8 & 0,0 & 111,3 & 289,5 & 283,7 \\
Amarela & 118,1 & 0,0 & 0,0 & 0,0 & 0,0 & 0,0 & 0,0 & 0,0 & 0,0 & 601,7 \\
Parda & 56,8 & 48,9 & 60,0 & 57,7 & 55,8 & 60,1 & 63,8 & 51,9 & 59,3 & 82,6 \\
Indígena & 0,0 & 0,0 & 0,0 & 0,0 & 0,0 & 0,0 & 0,0 & 0,0 & 501,8 & 0,0 \\
\hline & & & & & & & & & & \\
\hline
\end{tabular}




\begin{tabular}{|c|c|c|c|c|c|c|c|c|c|c|}
\hline \multicolumn{11}{|c|}{$\begin{array}{l}\text { RIOGRANDE } \\
\text { DO NORTE }\end{array}$} \\
\hline Cor/Raça & 2000 & 2002 & 2004 & 2006 & 2008 & 2010 & 2012 & 2014 & 2016 & 2017 \\
\hline Branca & 50,4 & 25,3 & 20,2 & 8,0 & 28,5 & 20,4 & 73,4 & 61,9 & 67,4 & 75,6 \\
\hline Preta & 150,3 & 0,0 & 179,5 & 0,0 & 374,7 & 0,0 & 99,6 & 118,8 & 320,2 & 0,0 \\
\hline Amarela & 0,0 & 0,0 & 0,0 & 0,0 & 0,0 & 0,0 & 0,0 & 0,0 & 0,0 & 0,0 \\
\hline Parda & 46,3 & 49,3 & 25,3 & 19,7 & 34,8 & 38,5 & 62,3 & 79,2 & 38,3 & 45,9 \\
\hline Indígena & 0,0 & 793,3 & 0,0 & 0,0 & 0,0 & 0,0 & 0,0 & 0,0 & 0,0 & 0,0 \\
\hline \multicolumn{11}{|l|}{ PARAÍBA } \\
\hline Cor/Raça & 2000 & 2002 & 2004 & 2006 & 2008 & 2010 & 2012 & 2014 & 2016 & 2017 \\
\hline Branca & 28,7 & 18,8 & 9,9 & 25,2 & 38,8 & 28,5 & 37,0 & 72,3 & 45,0 & 60,9 \\
\hline Preta & 0,0 & 304,7 & 157,1 & 188,6 & 553,6 & 561,3 & 324,9 & 0,0 & 212,6 & 0,0 \\
\hline Amarela & 0,0 & 0,0 & 0,0 & 0,0 & 0,0 & 0,0 & 0,0 & 0,0 & 835,3 & 0,0 \\
\hline Parda & 38,7 & 65,6 & 76,3 & 45,4 & 61,4 & 58,2 & 59,0 & 71,1 & 70,9 & 56,4 \\
\hline Indígena & 0,0 & 0,0 & 0,0 & 0,0 & 0,0 & 0,0 & 0,0 & 0,0 & 0,0 & 1273,5 \\
\hline \multicolumn{11}{|c|}{ PERNAMBUCO } \\
\hline Cor/Raça & 2000 & 2002 & 2004 & 2006 & 2008 & 2010 & 2012 & 2014 & 2016 & 2017 \\
\hline Branca & 23,4 & 29,1 & 38,0 & 29,7 & 40,0 & 47,7 & 66,0 & 42,0 & 35,5 & 74,6 \\
\hline Preta & 186,6 & 78,4 & 111,6 & 382,5 & 337,6 & 367,6 & 45,0 & 104,3 & 79,9 & 117,6 \\
\hline Amarela & 0,0 & 152,4 & 244,0 & 0,0 & 860,6 & 0,0 & 0,0 & 0,0 & 0,0 & 335,7 \\
\hline Parda & 44,6 & 43,7 & 68,8 & 51,6 & 66,9 & 61,3 & 42,3 & 52,8 & 46,2 & 47,0 \\
\hline Indígena & 0,0 & 0,0 & 0,0 & 247,8 & 0,0 & 0,0 & 0,0 & 0,0 & 0,0 & 0,0 \\
\hline \multicolumn{11}{|l|}{ ALAGOAS } \\
\hline Cor/Raça & 2000 & 2002 & 2004 & 2006 & 2008 & 2010 & 2012 & 2014 & 2016 & 2017 \\
\hline Branca & 50,8 & 33,6 & 60,0 & 82,2 & 53,1 & 109,5 & 61,1 & 176,5 & 0,0 & 40,7 \\
\hline Preta & 0,0 & 353,2 & 232,0 & 0,0 & 858,0 & 671,4 & 305,4 & 631,1 & 301,5 & 287,4 \\
\hline Amarela & 596,6 & 0,0 & 0,0 & 0,0 & 0,0 & 0,0 & 0,0 & 0,0 & 0,0 & 0,0 \\
\hline Parda & 42,9 & 40,6 & 52,6 & 43,4 & 55,1 & 52,1 & 46,9 & 68,7 & 49,1 & 31,7 \\
\hline Indígena & 0,0 & 0,0 & 0,0 & 0,0 & 0,0 & 0,0 & 0,0 & 0,0 & 0,0 & 0,0 \\
\hline \multicolumn{11}{|l|}{ SERGIPE } \\
\hline Cor/Raça & 2000 & 2002 & 2004 & 2006 & 2008 & 2010 & 2012 & 2014 & 2016 & 2017 \\
\hline Branca & 62,6 & 91,9 & 92,4 & 74,5 & 233,1 & 51,7 & 105,0 & 36,8 & 89,5 & 0,0 \\
\hline Preta & 174,2 & 0,0 & 726,3 & 561,3 & 825,6 & 0,0 & 326,4 & 81,2 & 254,0 & 158,3 \\
\hline Amarela & 0,0 & 0,0 & 0,0 & 0,0 & 0,0 & 0,0 & 0,0 & 0,0 & 0,0 & 0,0 \\
\hline Parda & 47,9 & 73,1 & 80,3 & 49,9 & 56,7 & 67,6 & 46,3 & 56,2 & 37,9 & 61,4 \\
\hline Indígena & 0,0 & 599,2 & 0,0 & 0,0 & 0,0 & 0,0 & 0,0 & 0,0 & 0,0 & 0,0 \\
\hline \multicolumn{11}{|l|}{ BAHIA } \\
\hline Cor/Raça & 2000 & 2002 & 2004 & 2006 & 2008 & 2010 & 2012 & 2014 & 2016 & 2017 \\
\hline Branca & 17,9 & 77,0 & 65,4 & 116,2 & 67,6 & 65,8 & 122,3 & 140,2 & 66,9 & 85,1 \\
\hline Preta & 248,8 & 234,4 & 274,7 & 357,1 & 501,1 & 659,4 & 78,9 & 162,6 & 86,6 & 146,4 \\
\hline Amarela & 0,0 & 0,0 & 0,0 & 0,0 & 0,0 & 0,0 & 0,0 & 194,5 & 0,0 & 0,0 \\
\hline Parda & 37,0 & 38,4 & 58,6 & 50,1 & 50,7 & 45,5 & 54,6 & 55,0 & 48,5 & 53,4 \\
\hline Indígena & 193,9 & 0,0 & 153,8 & 0,0 & 0,0 & 341,3 & 249,6 & 0,0 & 237,5 & 0,0 \\
\hline
\end{tabular}

Fontes: MS/SVS/CGIAE - Sistema de Informações sobre Mortalidade - SIM

MS/SVS/DASIS - Sistema de Informações sobre Nascidos Vivos - Sinasc 
A Figura 9 e na Figura 10 apresentam as TMM registradas na região Sudeste, com os estados dispostos de acordo com um critério aleatório nos agrupamentos dos gráficos. As taxas correspondentes às mulheres indígenas e cor/raça amarela apresentam alguns picos de destaque quando comparadas às taxas dos demais recortes de cor/raça para os estados do Espírito Santo, Minas Gerais e Rio de Janeiro, como resultado do sub-registro destas duas categorias em grande parte dos anos que compreendem a série com dados equivalentes a (zero). Permanece o destaque dos dados relacionados às taxas de mortalidade materna entre mulheres de cor/raça preta para os quatro estados da região, revelando um movimento de diminuição a partir de 2011, seguidos de oscilações pouco significativas. Embora as TMM de mulheres brancas demonstrem um movimento semelhante às TMM de mulheres pardas, as taxas de mulheres de cor/raça branca são as menores, quando comparadas às demais categorias de cor/raça.

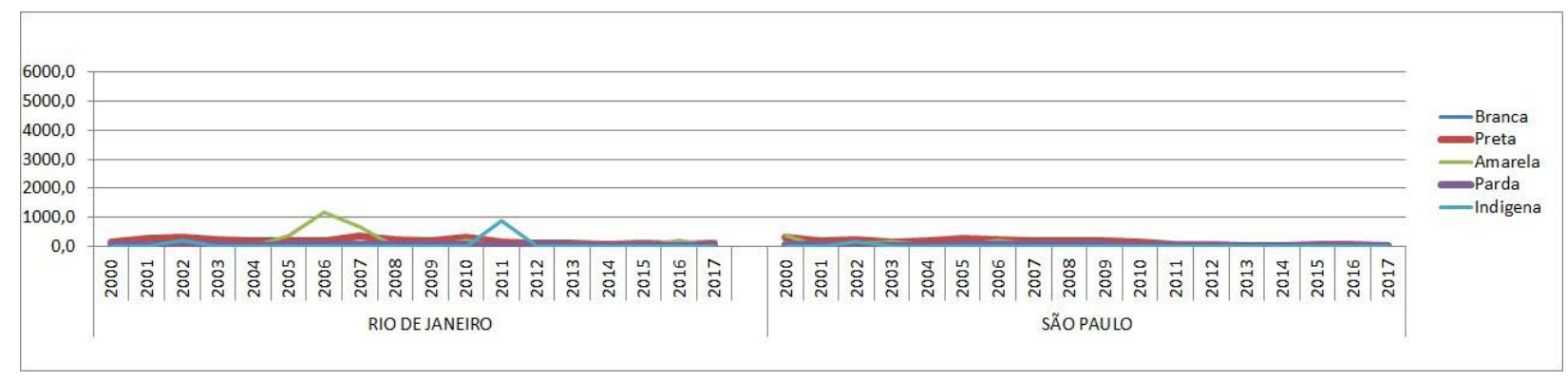

Figura 9 - Taxa de Mortalidade Materna, segundo Cor/Raça, p/ 100.000 hab. Região Sudeste, estados do Rio de Janeiro e São Paulo, 2000 a 2017

Fontes: MS/SVS/CGIAE - Sistema de Informações sobre Mortalidade - SIM

MS/SVS/DASIS - Sistema de Informações sobre Nascidos Vivos - Sinasc

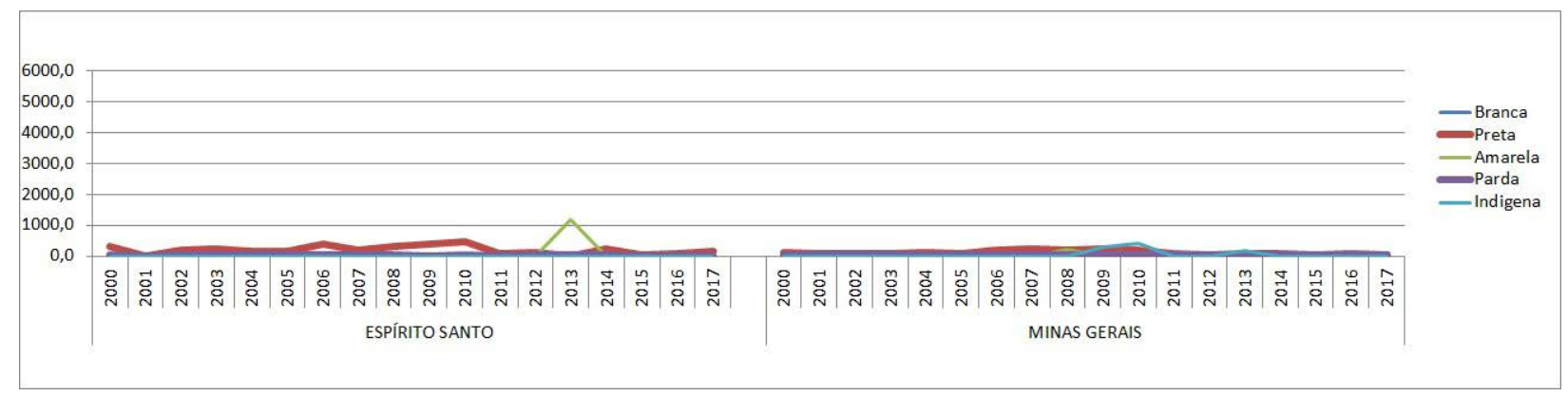

Figura 10 - Taxa de Mortalidade Materna, segundo Cor/Raça, p/ 100.000 hab. Região Sudeste, estados do Espírito Santo e Minas Gerais, 2000 a 2017

Fontes: MS/SVS/CGIAE - Sistema de Informações sobre Mortalidade - SIM

MS/SVS/DASIS - Sistema de Informações sobre Nascidos Vivos - Sinasc

A Figura 11, relacionado aos dados registrados na Região Sul apresenta picos, ora nas TMM de mulheres indígenas, ora nas taxas de cor/raça amarela ou com relação a ambas nos três estados, também em virtude do sub-registro de dados nestas duas classificações perceptíveis por meio dos dados com valores iguais a o (zero). Em Santa Catarina e no Rio Grande do Sul, as TMM de mulheres de cor/raça preta, parda e branca apresentam movimentos semelhantes, com exceção do Paraná, onde a TMM de mulheres de cor/raça preta se destaca até o ano de 2012, quando comparada às demais categorias de cor/raça. 


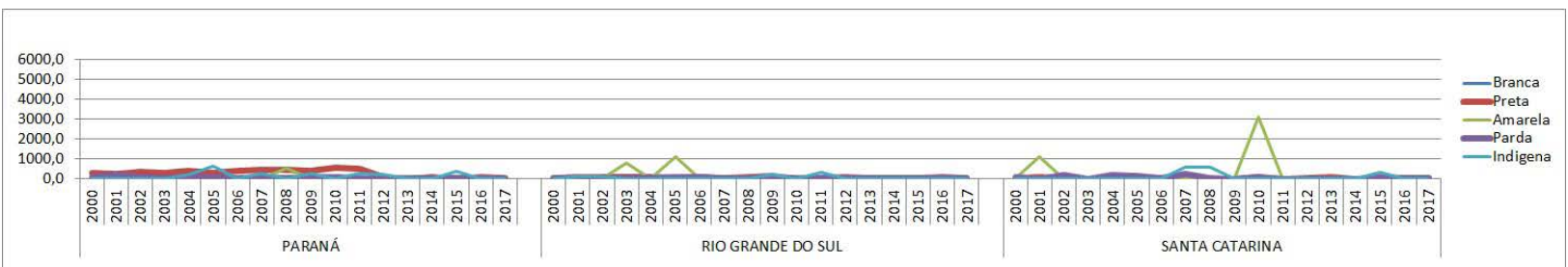

Figura 11 - Taxa de Mortalidade Materna, segundo Cor/Raça, p/ 100.000 hab. Região Sul, estados do Paraná, Rio Grande do Sul e Santa Catarina, 2000 a 2017

Fontes: MS/SVS/CGIAE - Sistema de Informações sobre Mortalidade - SIM

MS/SVS/DASIS - Sistema de Informações sobre Nascidos Vivos - Sinasc

Apesar das oscilações ao longo da série, é possível observar que a Figura 12 e a Figura 13, correspondentes às TMM dos estados - agrupados aleatoriamente - que compõem a Região Centro-Oeste apresentam as maiores TMM com relação às mulheres de cor/raça preta. Nos estados de Mato Grosso e Mato Grosso do Sul as segundas maiores TMM ao longo de toda a série estão relacionadas às mulheres indígenas. No Distrito Federal e em Goías, as TMM das mulheres indígenas ocorrem com destaque nos primeiros anos da série possivelmente pela ausência de notificação na quase totalidade dos anos subsequentes, justificando os valores iguais a o (zero) nos dados. Entre os quatro estados que compõem a região, Goiás foi o único que apresentou registros para o cálculo da TMM para a cor/raça amarela, de modo que Distrito Federal, Mato Grosso e Mato Grosso do Sul não apresentaram dados para o cálculo da taxa para este grupo de mulheres. O movimento da TMM de mulheres brancas e pardas é semelhante nos quatro estados que compõem a região.

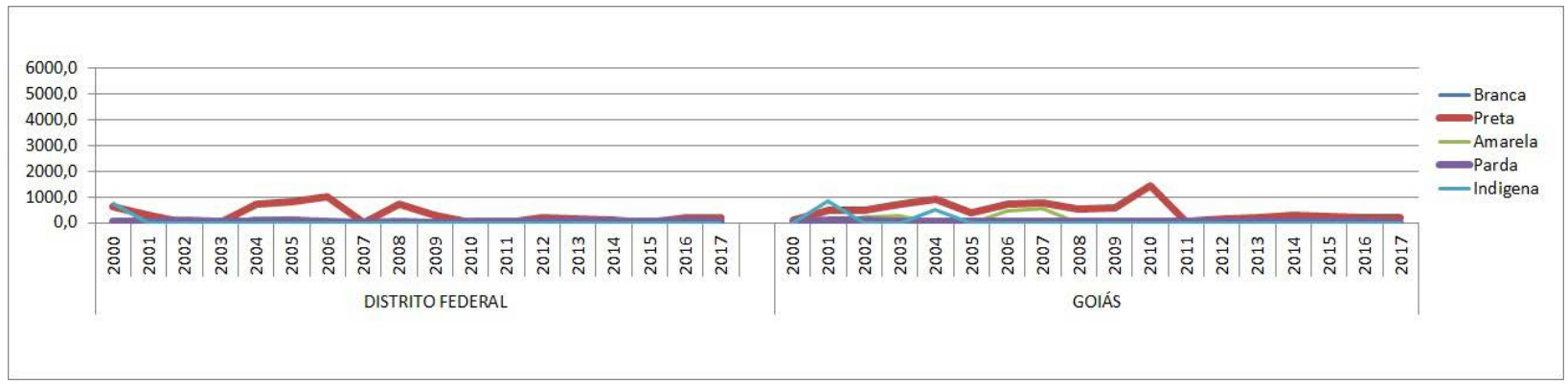

Figura 12 - Taxa de Mortalidade Materna, segundo Cor/Raça, p/ 100.000 hab. Região Centro-Oeste, Distrito Federal e estado de Goiás, 2000 a 2017

Fontes: MS/SVS/CGIAE - Sistema de Informações sobre Mortalidade - SIM

MS/SVS/DASIS - Sistema de Informações sobre Nascidos Vivos - Sinasc

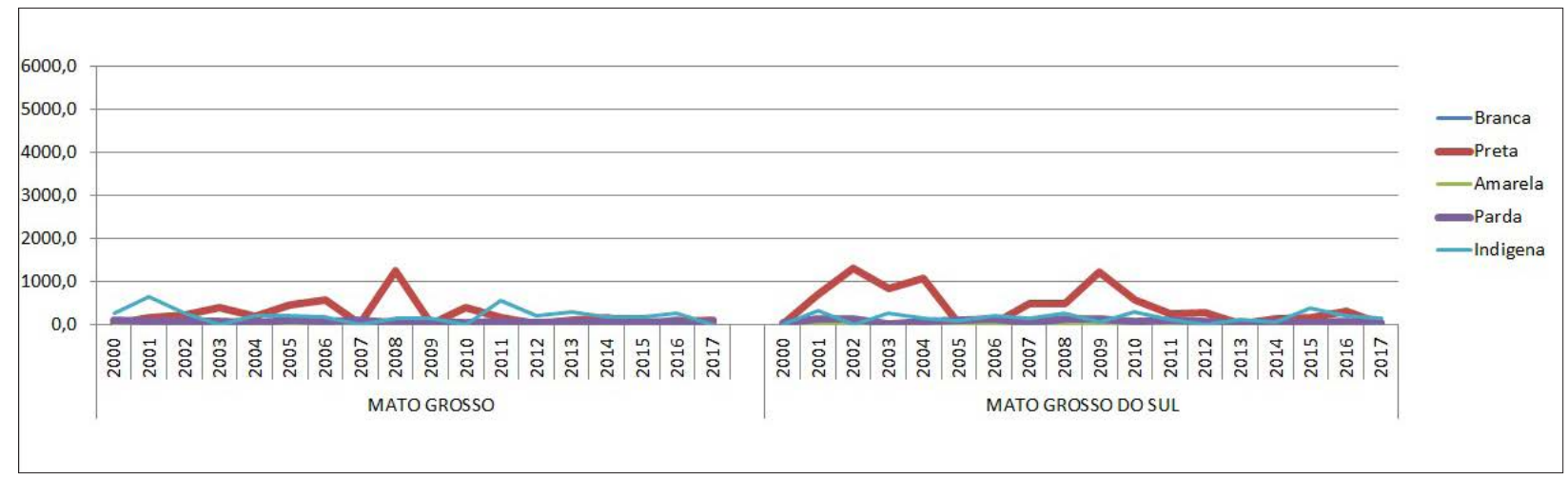

Figura 13 - Taxa de Mortalidade Materna, segundo Cor/Raça, p/ 100.000 hab. Região Centro-Óeste, estados do Mato Grosso e Mato Grosso do Sul, 2000 a 2017

Fontes: MS/SVS/CGIAE - Sistema de Informações sobre Mortalidade - SIM

MS/SVS/DASIS - Sistema de Informações sobre Nascidos Vivos - Sinasc 
A comprovação dos resultados apresentados nesta pesquisa não só gera um alerta para as disparidades entre as taxas de mortalidade materna, tão visíveis nos diversos recortes analíticos de cor/raça delimitados pelo IBGE, mas também reitera a evidência de que a ausência de registro ou o sub-registro dos dados nos sistemas de informação de saúde com relação aos recortes de cor/raça contribui para reforçar a vulnerabilidade de determinados grupos étnico-raciais minorizados na sociedade brasileira. Na verdade, aliada à desigualdade social, econômica, cultural e racial já posta na sociedade, ocorre uma desigualdade que perpassa o direito à informação e à saúde, exatamente por dificultar a elaboração de um retrato que represente o máximo possível a realidade por meio dos dados disponibilizados nos sistemas e de sua análise que fomentem mecanismos de reparação. Neste sentido, a ausência de um diagnóstico preciso dos registros limita a elaboração de soluções - seja no âmbito da gestão, dos treinamentos dos profissionais de saúde ou da implementação de políticas públicas mais direcionadas às particularidades de cada grupo étnico-racial - que contribuam para minimizar as desigualdades. Muitos dos dados registrados nos estados apresentam ausência de registros com relação às mulheres de cor/raça amarela, indígena e preta, revelando um déficit na percepção da importância de inserir estes registros e, consequentemente, revelando a importância da elaboração de análises que retratem com maior fidedignidade a diversidade e as condições sociais dos diversos grupos étnico-raciais do Brasil. Esta ressalva prévia é suficiente para atestar a necessidade de consolidação de treinamentos que valorizem a importância do registro de dados referentes a cor/raça como parte de um procedimento operacional padrão por parte dos profissionais de saúde para a inserção e publicização destes nos sistemas de informação em saúde.

\section{DISCUSSÃO}

Questões como equidade e acesso igualitário aos direitos têm sido largamente discutidas em diversas esferas da sociedade brasileira. É inegável que inúmeros avanços foram obtidos na legislação nacional, no Direito Internacional dos Direitos Humanos e nas políticas mais recentes de promoção da igualdade implementadas no Brasil, como resultado a incorporação dos princípios da Declaração Universal dos Direitos Humanos como elementos norteadores para a legislação interna brasileira. A Constituição Federal de 1988, no art. $5^{\circ}$, caput, afirma explicitamente, que "todos são iguais perante a lei, sem distinção de qualquer natureza" ${ }^{\prime 3}$. Apesar desses avanços, ganham visibilidade evidências de que persiste uma impermeabilização com relação aos discursos de defesa dos Direitos Humanos na sociedade brasileira que se espraiam no campo do direito à saúde. Sob esta perspectiva, um dos pressupostos para a efetividade da atenção integral à saúde da mulher está fundamentado na percepção de que os direitos sexuais e reprodutivos são direitos humanos, em conjunto com o reconhecimento de que dentro da diversidade da população feminina existem grupos com necessidades específicas ${ }^{26}$. É preciso levar em consideração o fato de que, em seu art. 196, a Constituição Federal também estabelece que "a saúde é um direito de todos e um dever do Estado"13 e que é conferido ao serviço público o papel de atender "sem violência, coerção ou qualquer tipo de discriminação e garantir que os serviços sejam acessíveis" ${ }^{13}$.

A despeito de todo o avanço percebido no âmbito das leis, o Brasil é um país que ainda não superou de forma plena as assimetrias raciais remanescentes do passado, expressas contemporaneamente em situações materiais que revelam a persistência do racismo e de desigualdades que são reveladas por meio de métodos de desagregação racial. A desigualdade institucionalizada entre negros e não negros no período escravista trouxe consequências ao nosso país que se prolongaram por gerações e que acarretam prejuízos sociais de proporções significativas no acesso igualitário à garantia dos direitos. Desde a instituição da ordem social escravocrata e mesmo após a sua queda, a sociedade brasileira manteve na sua estrutura valores que corroboraram as diversas expressões de desigualdade nas distintas esferas da vida social contra os grupos tidos como mais vulneráveis. E esta vulnerabilidade é materializada nos obstáculos ao acesso a 
uma diversidade de direitos, inclusive ao direito à informação e à saúde. O legado de alienação simbólica e material herdado historicamente pela população negra e indígena pode perpetuar a ausência de equidade nas suas condições de vida e saúde ${ }^{10}$.

Segundo a World Heath Organization (WHO) [Organização Mundial da Saúde (OMS)], 99\% das mortes relacionadas ao período da gestação, parto e puerpério ocorreram em países em desenvolvimento ${ }^{22}$. Um dos principais obstáculos no tratamento e análise de dados de mortalidade materna é a dificuldade no monitoramento da tendência da mortalidade materna no Brasil, em virtude de dois fatores que ocorrem nas Unidades Federativas (UF's): a subinformação e o sub-registro das declarações dos fatores que causaram o óbito ${ }^{1,23}$. A subinformação é resultado do preenchimento incorreto das declarações de óbito, especialmente quando a sua causa não está diretamente relacionada ao período da gestação, do parto ou do puerpério. $\mathrm{O}$ sub-registro consiste na omissão do registro de óbito em cartório, ocorrido muitas vezes pela dificuldade de acesso aos cartórios, pela utilização de cemitérios irregulares ou pela falta de disseminação da importância em emitir a certidão de óbitoํ. Semelhantemente, como ocorre com os dados de mortalidade materna em geral, também há obstáculos com relação à análise de dados de mortalidade materna no Brasil levando em consideração o recorte cor/raça em função da subnotificação do campo 'cor/raça' nas declarações de óbito. Mesmo constando na Declaração de Óbito, muitas vezes, o quesito cor/raça não é preenchido ou não corresponde à informação real ${ }^{26}$, resultando em dados com valores iguais a o (zero) Contudo, apesar da evidência de que ocorre subnotificação em dados desta natureza, é de grande importância a verificação da tendência dos dados que estão oficialmente disponíveis para estudo. A subinformação, a inexistência ou dificuldade no agrupamento de informações sobre a realidade da saúde da população negra nos sistemas de informação em saúde pode explicitar a concepção errônea de democracia racial no Brasil, expressa pelo não reconhecimento da inexistência de barreiras estruturalmente construídas que são explicitadas nas interações entre os indivíduos, seja no aspecto social, cultural ou racial. A negação da existência dessas barreiras desconstrói a própria concepção da sociedade brasileira como uma nação verdadeiramente democrática ${ }^{10}$ por retirá-la da pauta de discussão.

Estudos demonstram que pessoas pretas e pardas afirmaram ter percebido e sofrido discriminação nos serviços de atendimento à saúde, nos quais " $40 \%$ dos pretos e 40,5\% dos pardos perceberam discriminação, enquanto 7,0\% dos pretos e 6,1\% dos pardos relataram já terem sofrido discriminação"10. Estes estudos também identificaram pessoas de cor/raça preta que afirmaram ter desistido de procurar atendimento médico por não saberem onde poderiam encontrá-lo, reafirmando a necessidade de obterem um acesso mais eficiente à informação $0^{10}$ acerca dos direitos que lhe assistem e dos serviços que estão disponíveis. Os casos de desigualdade e discriminação no sistema de saúde também abrangem as mortes maternas. Entre os fatores que contribuem para a desigualdade no sistema de saúde, um elemento de destaque é o racismo institucional que invisibiliza as pessoas e que é explicitado por meio de práticas como o fato de alguns profissionais de saúde estigmatizarem as gestantes em virtude de seu status socioeconômico, de não darem ouvidos às necessidades das mulheres durante o parto e oferecerem um tratamento desigual, que fatalmente resulta numa sucessão de episódios mal-sucedidos que, no limite, resultam em óbito ${ }^{27}$. Esta lógica resulta em uma série de práticas que revelam tratamento diferenciado por meio de restrições de acesso aos serviços, baixa qualidade dos serviços que são oferecidos, a pouca informação da mulher sobre os seus próprios direitos, descaso com o quadro hipertensivo de mulheres negras no sistema de exames que antecedem o parto, atendimento desumanizado, a difusão do imaginário de que a mulher preta tem filhos com mais facilidade e que precisa de menos cuidado. Tudo isso aliado à indisponibilização de serviços de qualidade no pré-natal, parto e puerpério com relação a uma parcela da população de mulheres ou que deixam de ser oferecidos em função de sua cor, raça ou origem cultural ou étnica. Neste ponto, o racismo estrutural se converte em racismo institucional, perpetuando a desigualdade de oportunidades e a inexistência da equidade na vivência da população negra ${ }^{27}$. 
Segundo Martins, os casos de mortalidade materna ocorridos em território brasileiro atestam a intrínseca ligação entre o acesso à saúde e o acesso a direitos pertencentes a outras instâncias, de modo que mulheres acometidas pela morte materna são aquelas que possuem menor acesso à assistência, escolaridade e renda ${ }^{2}$ e que vivenciam opressões que se interseccionam e entrecruzam ${ }^{28,29}$. A morte materna no Brasil é concebida como um problema de direitos humanos e de saúde pública, pois atinge desigualmente mulheres pertencentes a classes sociais com menor acesso a bens sociais e econômicos nas diversas regiões do Brasil ${ }^{2}$. Quando o recorte racial é acrescentado às análises, é possível observar que as vivências das mulheres negras são marcadas por piores condições de vida e de saúde, exatamente por sua vulnerabilidade quando comparadas às demais. Deste modo é possível afirmar que as diferenças étnicas estão associadas a desigualdades sociais que se refletem na vida de pessoas e grupos específicos, assim como ocorre com as mulheres pretas, pardas e indígenas, comprovando a existência de uma conexão entre os dados e a desassistência à saúde de grupos sociais específicos ${ }^{22}$. Com relação a fatores relacionados à morbimortalidade nos grupos sociais, este fenômeno ocorre com padrões diferenciados entre os diversos grupos sociais em virtude da desigualdade em saúde, definida como "a distribuição desigual dos fatores de exposição, dos riscos de adoecer e morrer e do acesso a bens e serviços de saúde entre grupos populacionais distintos”30. Neste aspecto, "a etnia não é por si só fator de risco, mas a inserção social adversa do grupo racial constitui-se em vulnerabilidade" ${ }^{\prime 2}$. Estudos ${ }^{27}$ divulgam o diagnóstico de que as chances das mulheres pretas iniciarem o pré-natal tardiamente são maiores: 4,8\% iniciaram o acompanhamento da gravidez apenas no terceiro trimestre de gestação. As brancas que iniciaram seus exames tardiamente compreendem 3,1\%. Com relação ao atendimento no serviço público de saúde, as mulheres pretas apresentam maior probabilidade de nele serem atendidas neste tipo de serviço durante a gestação (85,8\%), ao passo que, entre as mulheres brancas, $57 \%$ fazem uso dele ${ }^{27}$.

Os estudos decorrentes da análise de dados dos sistemas de informação em saúde permitem a identificação das desigualdades que resultam em consequências diretas na saúde. Um exemplo é a maior incidência de doenças na população negra por fatores genéticos acrescidos a elementos de desigualdade socioeconômica ${ }^{10}$. As experiências vivenciadas pelas mulheres negras comprovam esta evidência. Devido à intersecção das discriminações de raça, gênero e classe social, torna-se maior o risco de a mulher negra ter seus conceitos de identidade pessoal, imagem corporal e autoestima prejudicados, de estar susceptível a fatores que contribuem para a redução da expectativa de vida ${ }^{26}$ exemplificados pela maior exposição à violência, pelos hábitos de vida insalubres e pela dificuldade no desenvolvimento de estratégias positivas de enfrentamento do estresse. À medida que o acesso aos dados é disponibilizado e as análises são desenvolvidas, aumentam as possibilidades de formulação de ações e políticas úteis à prevenção de mortes classificadas como evitáveis ${ }^{10}$. A morte materna, considerada pressupostamente evitável, ocorre como resultado da ausência ou de limitações no aperfeiçoamento de políticas específicas de saúde. E estas ausências ou limitações se refletem em intercorrências capazes de interferir diretamente na gestação e no parto ${ }^{22}$, ocasionando situações de altíssimo risco.

Os sistemas de informação em saúde possuem importância não só nas análises epidemiológicas, mas também para avaliar as políticas públicas implementadas a fim de prevenir e reparar a incidência de morte materna ${ }^{2}$. A disposição dos dados nos sistemas de informação em saúde configura-se como essencial neste processo, especialmente porque a ausência de publicização dos dados nestes sistemas ocasiona uma série de obstáculos na elaboração de ações de combate à desigualdade expressa nos dados de mortalidade materna segundo cor/raça. Em primeiro lugar, a ausência ou dificuldade no acesso aos dados nos sistemas de informação em saúde, violam o direito constitucional de acesso às informações públicas, assegurado pela Lei $n^{0}$ 12.527/2011, a Lei de Acesso à Informação. Em segundo lugar, a escassez dos dados de mortalidade materna com recorte racial étnico permite a perpetuação do uso de critérios meramente biológicos para o entendimento do processo saúde-doença ${ }^{22}$. Em terceiro lugar, a publicização dos dados referentes à morte 
materna é um componente essencial para o planejamento de programas de saúde sexual e reprodutiva, aliados às iniciativas e desenvolvimento de pesquisas destinados ao aprimoramento das redes de assistência à saúde materna ${ }^{22}$. Em quarto lugar, a publicização dos dados nos sistemas de informação em saúde enfatiza a relevância de um olhar intersetorial com relação a problemas previamente classificados como apenas 'de saúde pública', mas que revelam raízes estruturadas socialmente.

Para além dos dados de mortalidade, os dados socioeconômicos (condição socioeconômica, estado civil, escolaridade, condições de moradia, entre outros) são úteis uma vez que contribuem para a compreensão das condições de vida e de saúde destas mulheres ${ }^{2}$ e a identificação de possíveis soluções para minimização dos fatores que maximizam o risco com relação a este tipo de mortalidade. Do ponto de vista da reparação das desigualdades vivenciadas pela população negra, os estudos dos dados provenientes dos sistemas de informação em saúde são passíveis de contribuir para a implementação de medidas compensatórias específicas direcionadas à diminuição dos efeitos da discriminação e da exploração vivenciada por ela como legado histórico da sociedade brasileira, inclusive no âmbito da saúde ${ }^{10}$. Deste modo, a elaboração e o fortalecimento de políticas públicas voltadas para as pessoas em condições de vulnerabilidade, como forma de contribuir para a redução das desigualdades e diferenças ${ }^{3,10}$ precisa ocupar a agenda do País nos âmbitos federal, estadual e municipal.

A história brasileira comprova a importância da investigação das razões pela quais as pessoas morrem no processo de desenvolvimento e consolidação das ações no campo das políticas públicas em saúde 3 . Contudo, persistem os entraves à minimização dessas desigualdades, exemplificados pela percepção errônea dos profissionais de saúde de que a população negra não vivencia desigualdades que justifiquem políticas especiais, aliada ao julgamento equivocado de que a implementação de políticas especiais voltadas para a comunidade negra tende a reforçar a segregação e a discriminação racial no país ${ }^{10}$. Neste aspecto, o argumento principal dos profissionais de saúde que apresentam este olhar enviezado a respeito desta questão circula em torno da opinião de que todos os indivíduos são iguais por natureza, independentemente de sua raça, e de que qualquer política de reparação de direitos de um grupo racial representaria a concepção de um privilégio desnecessário. A desinformação com relação à variável cor/raça contribui para o ocultamento de informações extremamente relevantes no processo de monitoramento dos casos de discriminação racial no sistema de saúde 3 . E a análise das variáveis cor/raça nos sistemas de informação pode contribuir para trazer à reflexão a importância do aperfeiçoamento das etapas de planejamento, gestão e avaliação de políticas de atenção a grupos étnico-raciais específicos com vistas à redução das desigualdades e, consequentemente, à implementação de iniciativas que promovam efetivamente o desenvolvimento e a consolidação da equidade na sociedade brasileira.

\section{CONCLUSÃO}

De acordo com Domingues, Santos e Leal, "ao longo das últimas décadas, tem-se observado um movimento crescente de críticas ao modelo brasileiro de assistência ao parto e aos seus resultados, endossado mais recentemente pelo próprio Ministério da Saúde"31. Pesquisas recentes sobre a situação de saúde da mulher negra no Brasil têm identificado assimetrias e quando o recorte de cor/raça é realçado ${ }^{25,32,33}$, de modo que mulheres pretas e pardas constituem o grupo mais vulnerável ao óbito materno e mais suscetível de ser alvo de uma maior desassistência à saúde ${ }^{22}$.

Neste processo, a publicização dos dados com recorte de cor/raça no sistema de informação em saúde possui importância considerável para que, por meio das desigualdades identificadas, sejam identificados padrões de hierarquização de gênero e raça e de discriminações consideradas como pouco visíveis. As pesquisas de análise dos dados provenientes do sistema de informações identificam no cenário que circunda os dados coletados do sistema de informação em saúde, o fato de que é essencial lançar mecanismos de 
combate ao "potencial patogênico pouco visível nas discriminações" 22 ocorridas no cotidiano, inclusive nos processos discriminatórios que ocorrem no campo da saúde materna e que são perpassados por fatores como gênero, classe e raça ${ }^{22}$. O estudo destes dados contribui para a implementação de ações integradas de combate à discriminação e à exclusão da mulher negra no âmbito da saúde, combatendo a alienação dos direitos básicos destas mulheres, como o direito à vida e à saúde ${ }^{22}$. E isto porque a desinformação implica na falta de percepção da gravidade expressa nos dados de mortalidade materna - considerada evitável - e na ausência de conhecimento com relação às reais causas que resultam na morte das mulheres, dificultando o planejamento de ações que visem à redução desta mortalidade ${ }^{22}$.

Estudos ${ }^{22,26}$ apontam para evidências de uma relação direta entre um atendimento de má qualidade e as condições de vida das mulheres de cor preta e parda. Entre estas evidências, é possível observar: complicações decorrentes de hemorragia e infecção e a atuação de profissionais não competentes; uma possibilidade menor de intervenção cirúrgica como uma tentativa de reparação de complicações resultantes do parto; a influência da baixa escolaridade dessas mulheres na qualidade da assistência obstétrica que lhes é oferecida; o acesso limitado à educação em saúde, principalmente com relação à transmissão de informações referentes aos benefícios do parto normal como forma de reduzir procedimentos desnecessários como a cesariana durante o parto; a falta de ações e de capacitação de profissionais de saúde com o objetivo de atender aos riscos decorrentes dos fatores de predisposição biológica das mulheres negras para desenvolverem doenças como hipertensão arterial, anemia falciforme, diabetes mellitus, pré-eclâmpsia, hemorragia, complicações cardiovasculares e infecções ${ }^{22,26}$. O desvio do olhar dos profissionais de saúde com relação a estes aspectos reitera a prática de um atendimento de baixa qualidade sem que sejam levados em consideração os elementos de risco aos quais mulheres estão expostas. Quando isso ocorre, os saberes profissionais da saúde se sobrepõem aos saberes da experiência vivida no próprio corpo pelas mulheres durante o ciclo gravídico-puerperal. Consequentemente, se desvanece na compreensão desses profissionais a imagem da mulher como portadora de direitos, inclusive, de direitos sobre seu próprio corpo. Assim, por questões sociais ou relacionadas à discriminação, as mulheres negras têm menor acesso aos serviços de boa qualidade, a serviços de atenção à sua saúde ginecológica e ao atendimento de atenção obstétrica ${ }^{26}$.

Os sistemas de informação de saúde também são capazes de fornecer indicativos de ordem socioeconômica com potencial para contribuir no aprofundamento da reflexão acerca das desigualdades ocorridas no sistema público de saúde. Com relação aos perfis das mulheres negras que são alvo de mortalidade materna, Benevides identificou entre as vulnerabilidades: o fato de que a maioria das negras encontra-se abaixo da linha da pobreza e possui uma taxa de analfabetismo duas vezes maior que as mulheres brancas; a evidência de que a maioria das mulheres negras que sofreram mortalidade materna, na maioria, estavam constituídas como chefes de família com filhos e sem cônjuges (de modo que as crianças nascidas de mães negras falecidas apresentam maior risco de orfandade) ${ }^{26}$.

A possibilidade de acesso e análise dos dados provenientes da publicização dos registros dos sistemas de informação em saúde também permite a possibilidade de implementação de iniciativas relacionadas ao oferecimento de uma atenção com maior qualidade por órgãos das diversas instâncias (municipal, estadual e federal), entre elas: a manutenção da variável cor/raça nos dados de mortalidade e nos registros dos nascidos; a aplicação da perspectiva étnico-racial nas políticas já existentes (na Rede Cegonha, por exemplo); a valorização de profissionais como a doula e as parteiras; a implementação de políticas públicas especificamente direcionadas à atenção e à saúde da mulher; o oferecimento de atendimento humanizado no pré-natal e nascimento/ o acompanhamento dos casos de aborto; a ampliação e consolidação do monitoramento dos dados sociais; a formação humanizada dos profissionais de saúde (por meio de uma educação continuada e permanente, operando a aplicação de estratégias dos direitos humanos por meio de documentos que atestem o compromisso de ajustamento de conduta); a supervisão de todo o processo de gestão com a intervenção das organizações internacionais e do Ministério Público; o apoio ao fomento de 
projetos que visam à redução da mortalidade materna; a concessão de assistência jurídica em ações judiciais civis indenizatórias de caráter individual; e a implementação de treinamentos que visem à sensibilização dos profissionais de saúde, inclusive com relação à etapa de registro e análise dos dados sobre as variáveis raça, cor e/ou etnia ${ }^{2,34}$.

Por fim, existem passos significativos no processo de acolhimento com qualidade das gestantes e recémnascidos negros ${ }^{26}$ como: conferir maior visibilidade das mulheres negras por meio do registro e divulgação de dados e treinamentos que tragam à discussão as características específicas dessas mulheres; a realização de ações educativas que contemplem a identificação das especificidades, riscos e cuidados específicos voltados para esse grupo e a implementação de atividades de atenção às gestantes e suas famílias. Iniciativas como estas necessitam de aplicação como forma de aproximar as usuárias da rede aos profissionais e de promover mecanismos de sensibilização do sistema público de saúde como um todo - tanto no que diz respeito ao combate ao racismo institucional quanto à conscientização dos profissionais da saúde acerca da reprodução da estrutura social brasileira (racista, classista e patriarcal) - como estratégias de facilitação do acesso a uma série de direitos (aos direitos humanos, aos direitos fundamentais previstos na Constituição Federal de 1988, ao direito à informação, ao direito à saúde, entre outros). Embora diversos, estes direitos se complementam nos objetivos finais de minimizar as desigualdades e de contribuir para a efetivação do acesso à equidade e da consolidação da democracia na sociedade brasileira.

\section{REFERÊNCIAS}

1. Ministério da Saúde (BR). Secretaria de atenção à saúde, Departamento de ações programáticas estratégicas. Manual dos comitês de mortalidade materna [Internet]. Brasília (DF): Editora do Ministério da Saúde; 2007 [citado 20 ago 2019]; 104 p. Disponível em: http://bvsms.saude.gov.br/bvs/ publicacoes/manual comites mortalidade materna.pdf.

2. Martins AL. Mortalidade materna de mulheres negras no Brasil. Cad. Saúde Pública [Internet]. 2006 Nov [citado 2019 ago 19];22(11):2473-79. Disponível em: http://www.scielo.br/scielo. php?script=sci arttext\&pid=S0102-311X2006001100022\&lng=en. doi: http://dx.doi.org/10.1590/S0102$\underline{311 \times 2006001100022}$.

3. Adorno RCF, Alvarenga AT, \& Vasconcellos MP. Quesito cor no sistema de informação em saúde. Estud. av. [Internet]. 2004 Abr [citado 2019 ago 19];18(50):119-23. Disponível em: https://dx.doi. org/10.1590/S0103-40142004000100011.

4. Guimarães ASA. Racismo e anti-racismo no Brasil. Novos Estudos [Internet]. 1995 [citado 2019 dez 15];43:26-44. Disponível em: https://edisciplinas.usp.br/pluginfile.php/4116181/mod resource/ content/0/A.\%20S.\%20Guimar\%C3\%A3es\%20-\%20Racismo\%20e\%20anti-racismo\%20no\%20Brasil. pdf.

5. Jaccoud L. O combate ao racismo e à desigualdade: o desafio das políticas públicas de promoção da igualdade racial. In: Theodoro M., organizador. As políticas públicas e a desigualdade racial no Brasil: 120 anos após a abolição. Brasília: Ipea; 2008. p.131-66.

6. Lima M. Desigualdades raciais e políticas públicas: ações afirmativas no governo Lula. Novos estudos Cebrap [Internet]. 2010 [citado 2019 ago 19];(87):77-95. Disponível em: https://dx.doi.org/10.1590/ S0101-33002010000200005.

7. Maio MC, Monteiro S. Tempos de racialização: o caso da 'saúde da população negra' no Brasil. Hist. cienc. saude-Manguinhos [Internet]. 2005 Ago [citado 19 ago 2019];12(2):419-446. Disponível em: http://www.scielo.br/scielo.php?script=sci arttext\&pid=S0104-59702005000200010\&lng=en.

8. Thompson JB. Ideologia e cultura moderna - teoria social crítica na era dos meios de comunicação de massa. Petrópolis, RJ: Vozes; 2007.

9. Oliveira VDC. A comunicação midiática e o Sistema Único de Saúde. Interface (Botucatu) [Internet]. 2000 [citado 2019 ago 19];4:71-80. Disponível em: https://www.scielo.br/scielo.php?script=sci arttext\&pid=S1414-32832000000200006\&lng=pt\&tlng=pt. doi: http://dx.doi.org/10.1590/S1414$\underline{32832000000200006}$. 
10. Chehuen Neto JA, Fonseca GM, Brum IV, Santos JLCT, Rodrigues TCGF, Paulino KR, Ferreira, Renato RE. Política Nacional de Saúde Integral da População Negra: implementação, conhecimento e aspectos socioeconômicos sob a perspectiva desse segmento populacional. Ciênc. saúde coletiva. [Internet]. 2015 Jun [citado 2019 ago 19 ];20(6):1909-16. Disponível em: http://www.scielo.br/scielo.php?script=sci arttext\&pid=S1413-81232015000601909\&lng=en.

11. Brasil. Decreto Federal no 65.810, de 8 de dezembro de 1969. Promulga a Convenção Internacional sobre a Eliminação de todas as Formas de Discriminação Racial. Diário Oficial da União; 1969; 9 dez.

12. Theophilo RL, Rattner D; Pereira EL. Vulnerabilidade de mulheres negras na atenção ao pré-natal e ao parto no SUS: análise da pesquisa da Ouvidoria Ativa. Ciênc. saúde coletiva [Internet]. 2018 Nov [citado 2019 ago 19];23(11):3505-16. Disponível em: http://www.scielo.br/scielo.php?script=sci arttext\&pid=S $141381232018001103505 \&$ lng=pt.

13. Brasil. Constituição da República Federativa do Brasil [Internet]. Brasília, DF, Senado; 1988 [citado 19 ago 2019]; Disponível em: http://www.planalto.gov.br/ccivil 03/constituicao/constituicao.htm.

14. Brasil. Portaria no 1.459, de 24 de junho de 2011. Institui no âmbito do Sistema Único de Saúde a Rede Cegonha. Diário Oficial da União; 2011; 25 jun.

15. Hoffman KM, Travalter S, Axt JR, Oliver MN. Racial bias in pain assessment and treatment recommendations, and false beliefs about biological differences between blacks and whites. Proceedings of the National Academy of Sciences [Internet]. 2016 [citado 2019 ago 19];113(16):4296-4301. Disponível em: https://www.ncbi.nlm.nih.gov/pubmed/27044069.

16. Leal MC, Gama SGN, Pereira APE, Pacheco VE, Carmo CN, Santos RC. A cor da dor: iniquidades raciais na atenção pré-natal e ao parto no Brasil. Cad. Saúde Pública. [Internet]. 2017 [citado 2019 ago 19];33(Suppl 1):e00078816. Disponível em: http://www.scielo.br/scielo.php?script=sci arttext\&pid=S0102-311X2017001305004\&lng=en. doi: http://dx.doi.org/10.1590/0102-311x00078816.

17. Brasil. Ministério da Saúde. Secretaria de Gestão Estratégica e Participativa. Departamento de Apoio à Gestão Participativa e ao Controle Social. Política Nacional de Saúde Integral da População Negra: uma política para o SUS / Ministério da Saúde, Secretaria de Gestão Estratégica e Participativa, Departamento de Apoio à Gestão Participativa e ao Controle Social. 3 ed. Brasília : Editora do Ministério da Saúde; 2017. Disponível em: http://bvsms.saude.gov.br/bvs/publicacoes/politica nacional saude populacao negra 3d.pdf.

18. Silva GM, Rasera EF. A construção do SUS-problema no jornal Folha de S.Paulo. Hist. cienc. saudeManguinhos [Internet]. 2014 [citado 2019 ago 19];21(1):1-15. Disponível em: http://www.scielo.br/ scielo.php?script=sci arttext\&pid=S0104-59702014000100061\&lng=en. doi: http://dx.doi.org/10.1590/ $\underline{\text { S0104-59702013005000012. }}$

19. Lefèvre F, Lefèvre AMC. Promoção de saúde, ou a negação da negação. Rio de Janeiro: Vieira \& Lent; 2004.

20. Sodré M. Eticidade, campo comunicacional e midiatização. In: Moraes D., organizador. Sociedade midiatizada. Rio de Janeiro: Maud; 2006.

21. Fausto Neto, A. Midiatização, prática social - prática de sentido. In: Encontro da rede Prosul comunicacação, sociedade e sentido (2005), São Leopoldo. Anais..., São Leopoldo; 2005.

22. Teixeira NZF, Pereira WR, Barbosa DA, Vianna LAC. Mortalidade materna e sua interface com a raça em Mato Grosso. Rev. Bras. Saude Mater. Infant. [Internet]. 2012 Jan./Mar [citado 2019 ago 19];12(1):27-35. Disponivel em: https://www.scielo.br/scielo.php?script=sci arttext\&pid=S151938292012000100003\&lng=pt\&tlng=pt. http://dx.doi.org/10.1590/S1519-38292012000100003.

23. Volochko A. A mensuração da mortalidade materna no Brasil. In: Berquó E. Sexo \& vida: panorama da saúde reprodutiva no Brasil. Campinas, SP: Editora da Unicamp; 2003. p. 229-56.

24. Laurenti R. Perfil da mortalidad materna. In: Minayo MCS, organizadora. Os muitos Brasis: saúde e população na década de 80. São Paulo/Rio de Janeiro: Hucitec-Abrasco; 1995.

25. Paixão M, Rosseto I, Montovanele F, Carvano LM. Relatório anual das desigualdades raciais no Brasil (2009-2010): Constituição cidadã, seguridade social e seus efeitos sobre as assimetrias de cor ou raça. Rio de Janeiro: Laeser; Garamond Universitária; 2010. p. 292. Disponível em: http://www.palmares.gov. br/wp-content/uploads/2011/09/desigualdades raciais 2009-2010.pdf. 
26. Benevides MAS, Martins AL, Cruz ICF, Oliveira MF. Ministério da Saúde. Secretaria de atenção à saúde. Departamento de ações programáticas estratégias. Perspectiva da Equidade no Pacto Nacional pela redução da mortalidade materna e neonatal: Atenção à saúde das mulheres negras [Internet]. $1^{a}$ reimpressão. Série F. Comunicação e Educação em Saúde. Brasília/DF, 2005 [citado 20 ago 2019]; 20 p. Disponível em: http://bvsms.saude.gov.br/bvs/publicacoes/perspectiva equidade pacto nacional.pdf.

27. Ferreira L. Mães mortas: onde falha o sistema de saúde que negligencia a vida das mulheres negras: Taxa de mortalidade de mulheres pretas dos últimos 10 anos é o dobro da de mulheres brancas [Internet]. 2018 Set [citado 20 ago 2019]; p.1-18. Disponível em: http://www.generonumero.media/ racismo-mortalidade-materna/.

28. Creenshaw K. Documento para o encontro de especialistas em aspectos da discriminação racial relativos a gênero. Rev. Estud. Fem. [Internet]. 2002 [citado 2019 ago 25];10(1):171-88. Disponível em: https:// dx.doi.org/10.1590/S0104-026X2002000100011.

29. López LC. Mortalidade materna, movimento de mulheres negras e direitos humanos no Brasil: um olhar na interseccionalidade de gênero e raça. Tomo [Internet]. jan-jun 2016 [citado 2019 ago 25];28:135-67. Disponível em: https://seer.ufs.br/index.php/tomo/article/view/5424.

30. Duarte EC, Schneider MC, Paes-Sousa R, Ramalho WM, Sardinha LMV, Silva Junior JB, Castillo-Salgado C. Epidemiologia das desigualdades em saúde no Brasil: um estudo exploratório [Internet]. Brasília: Organização Pan-Americana da Saúde, 2002 [citado 2019 ago 19]; 123 p. Disponível em: http:// repositorio.unb.br/bitstream/10482/12955/1/LIVRO Epidemologia Desigualdades.pdf.

31. Domingues RMSM, Santos EM, Leal MC. Aspectos da satisfação das mulheres com a assistência ao parto: contribuição para o debate. Cad. Saúde Pública [Internet]. 2004 [citado 2019 ago 19];20:S52-S62. Disponível em: https://www.scielo.br/scielo.php?script=sci arttext\&pid=S0102-311X20 04000700006\&lng=pt\&tIng=pt. doi: $\underline{\text { http://dx.doi.org/10.1590/S0102-311X2004000700006. }}$.

32. Santos SN, Guimarães MJB, Araújo TVB. Desigualdades raciais na mortalidade de mulheres adultas no Recife, 2001 a 2003. Saúde Soc. [Internet]. 2007 [citado 2019 ago 19 ];16(2):87-102. Disponível em: https://www.scielo.br/scielo.php?script=sci arttext\&pid=S0104-12902007000200009\&lng=pt\&tlng=pt. doi: http://dx.doi.org/10.1590/S0104-12902007000200009.

33. Cruz ICF. A sexualidade, a saúde reprodutiva e a violência contra a mulher negra: aspectos de interesse para assistência de enfermagem. Rev. esc. enferm. USP [Internet]. 2004 [citado 2019 ago 19];38(4):448-57. Disponível em: https://www.scielo.br/scielo.php?script=sci arttext\&pid=S008062342004000400011\&lng=pt\&tlng=pt. doi: $\underline{\text { http://dx.doi.org/10.1590/S0080-62342004000400011. }}$.

34. Borges L. Maternidade materna: uma questão de raça na saúde pública [Internet]. Workshop da Secretaria de Políticas de Ações Afirmativas, Secretaria de Políticas de Promoção da Igualdade Racial, Brasília: DF; Jun 2015 [citado 2019 ago 19]. Disponível em: https://www2.camara.leg.br/atividadelegislativa/comissoes/comissoespermanentes/ cssf/audiencias-publicas/audiencia-publica-2015/aud-0906-subpasne/apresentacao-3. 